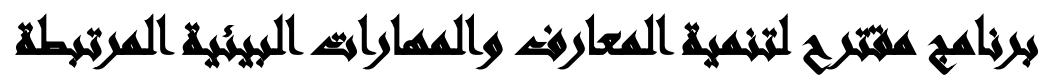

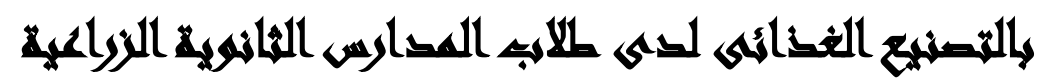

[11]

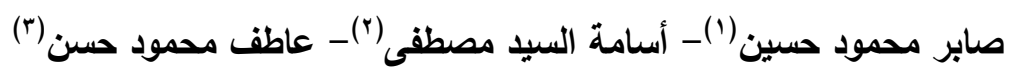

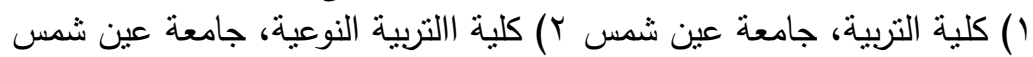
r) وزارة التربية والتعليم التربية هامعة

\section{المستخلصف}

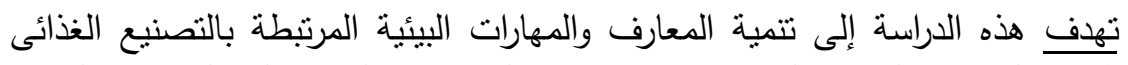

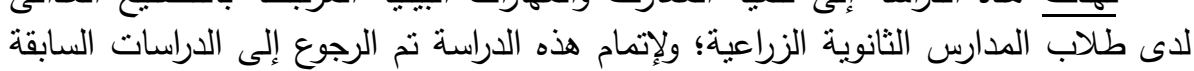

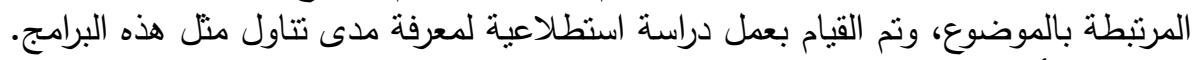

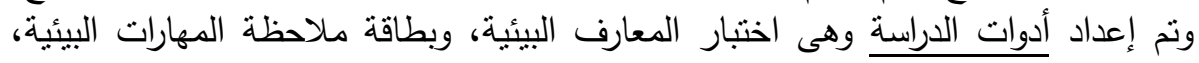

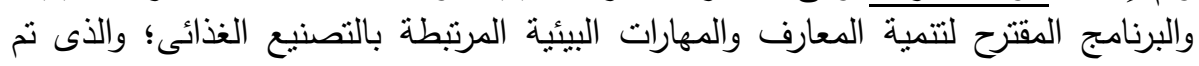

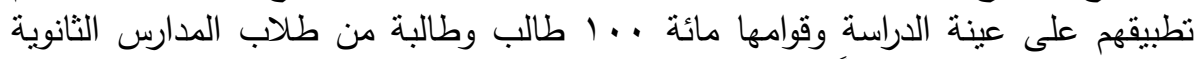

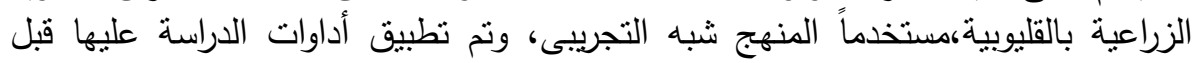

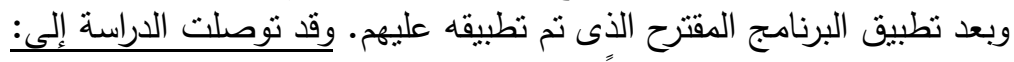

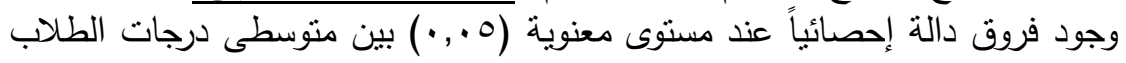

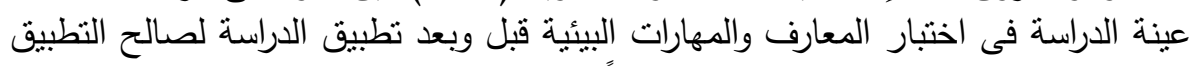

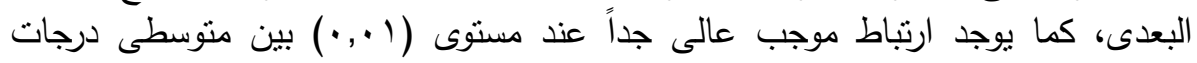

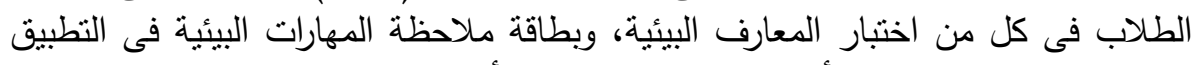

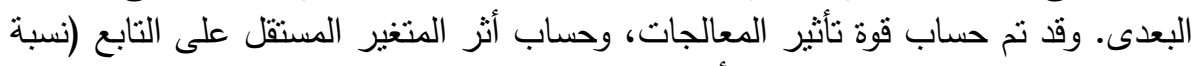

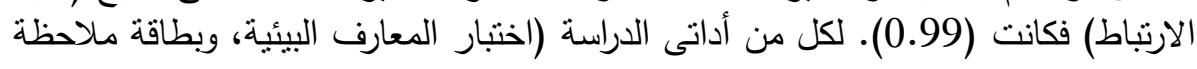

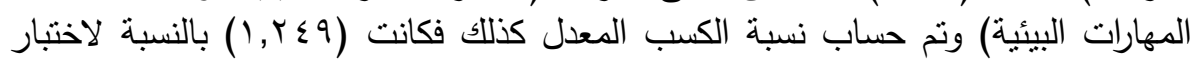

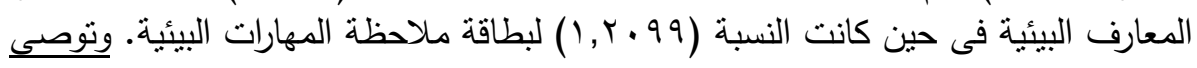
الدراسة:

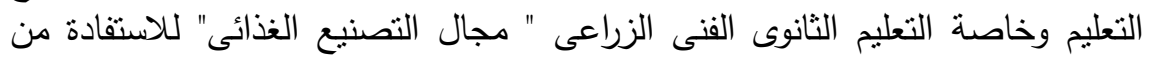
البرنامج المقترح وخائ

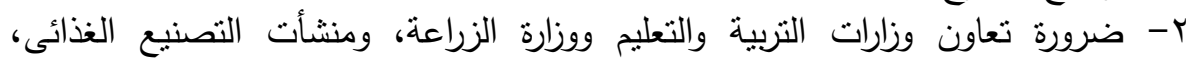
والجهات المسئولة عن الثروة الحيوانية، والنباتية، والصناعاعات الزراعة الغذائية، والصناعات الغنات

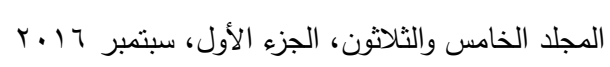


المغذية، والمكملة لها لخدمة طلاب المدارس الثانوية الزراعية بما يفيدهم وينمى معارفهم

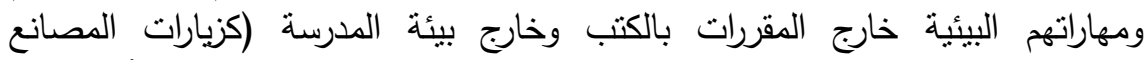

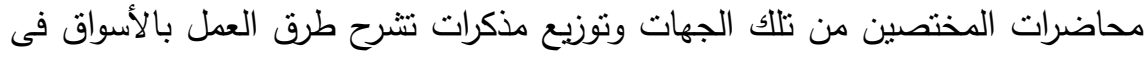
مجال التصنيع الغذائى). r- انباع طرق التدريس الحديثة، والمنتوعة بالاستعانة بالوسائل التكنولوجية، والزيارات الميدانية، بعيداً عن الطرق التقليدية للتنريس فى مدارس التعليم الزراعى. بالنى

\section{المخدهد}

أبدع الإنسان فى تصنيع العديد والعديد من أنواع وأصناف الأغذية فى إطار تطور احتياجاته من الغذاء، وتهتم أجهزة الدولة بوزاراتها وعلى رأسها وزارة التربية والتعليم لاسيما التعليم الفنى الزراعى الذى يهدف إلى تخريج الفنى والمتخصص فى المجالات الزراعية، ومجال التصنيع الغذائى بصفة خاصة، وهناك أكثر من مقرر فى التعليم الزراعى بمجال التصنيع الغذائى يوافى احتياجات الطلاب من المعارف فى الحياة العامة، وحياتهم الدراسية وهنية فى هذا المجال، ولأن من مبادئ التربية البيئية الرئيسة؛ إسهام كل المواد الدراسية والأنشطة

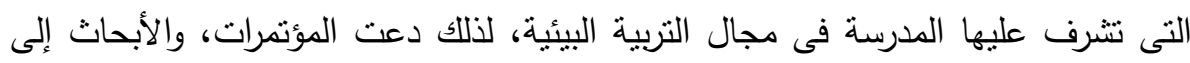

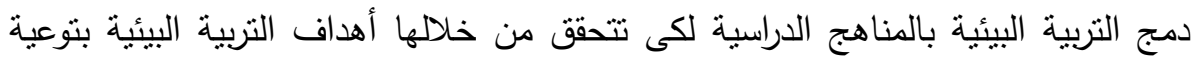

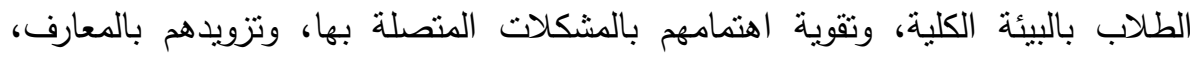
والمهارات البيئية؛ للحيلولة دون ظهور مشكلات بيئية جديدة.(هدى عوض الله: . . ب).

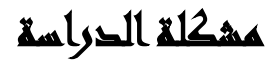

تتبلور مشكلة الدراسة فى أن الطلاب بالمدارس الثانوية الزراعية نظام الثلاث سنوات

لديهم تدنى فى المعارف والمهارات البيئية مرتبطة بالتصنيع الغذائى. وهذا يتضح بعد الدراسة الاستطلاعية التى تم القيام بها على أربعين •ــ طالباً بمدرسة مسطرد الثانوية الزراعية للبنين، إدارة شرق شبرا الخيمة التعليمية بالقليوبية، نم خلالها تتفيذ اختبار مقنن يتكون من خمسة وعشرين (Y0) سؤال يقيس مستوى المعارف البيئية بواقع كل سؤال درجة 
واحدة، نم توزيعه على هؤلاء الطلاب لقياس مستوى المعارف البيئية المرنبطة بمجال

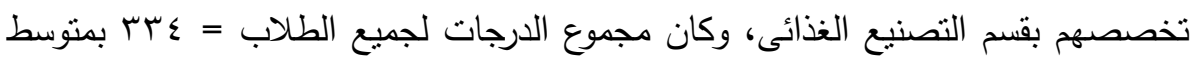

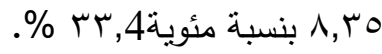

وقد تم خلال تلك الدراسة الاطلاع على الأنشطة التى تقدم للطلاب والمرتبطة بتخصصهم كما تم تتفيذ لقاءات فى صورة حوارات مفتوحة مع الطلاب وجد تدنى مستوى المعارف البيئية لديهم. ومن خلال الدراسات السابقة التى تم الاطلاع عليها والمرتبطة بشقى الدراسة ا(لتصنيع

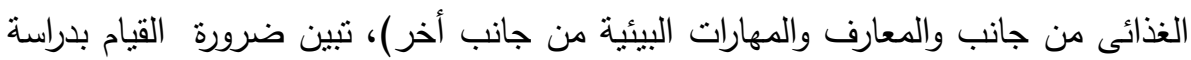
تعالج هذا القصور ، وهذا مما حدا بالباحثين للقيام بهذه الدراسة.

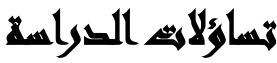

سؤال رئيس: ما شكل ومحتوى برنامج لتتمية المعارف والمهارات البيئية المرتبطة بالتصنيع الغذائى لدى طلاب المدارس الثانوية الزراعية؟ وتفرع عن هذا السؤال الأسئلة الآتية:

س ا ما المعارف والمهارات البيئية الواجب توافرها لدى طلاب المدارس الثانوية الزراعية؟ س r ما مدى توفر المعارف والمهارات البيئية المرتبطة بالتصنيع الغذائى والتى تم التوصل إليها بمنهج طلاب المرحلة الثانوية الزراعية؟ مانج

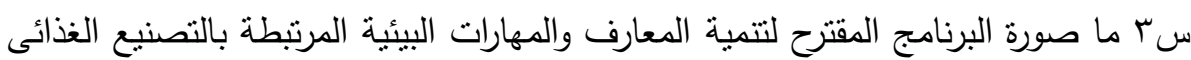

$$
\text { لاى طلاب المدارس الثانوبة الزراعية؟ لمانج }
$$

سء ما فاعلية البرنامج المقترح فى تتمية المعارف البيئية المرتبطة بالتصنيع الغذائى لدى

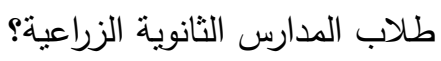

سه ما فاعلية البرنامج المقترح فى تتمية المهارات البيئية المرتبطة بالتصنيع الغذائى لاى لزىرئي

$$
\text { طلاب المدارس الثانوية الزراعية؟ }
$$

$$
\text { المجلد الخامس والثلاثون، الجزء الأول، سبتمبر } 17 \text {. }
$$




\section{همبهن القراسما}

تهدف الدراسة إلى: تتمية المعارف والمهارات البيئية المرتبطة بالتصنيع الغذائى لدى طلاب

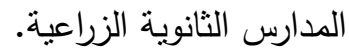

\section{أهمية التراسلة}

يتوقع الباحث أن تقيد هذه الدراسة فيما تقدمه للجهات المستقيدة منها: 1- مخططى المناهج: فى تضمين المعارف والمهارات البيئية بمناهج التعليم الثانوى

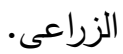

ץ- المعلمون: عند تقويم الطلاب باستخدام اختبار المعارف وبطاقة ملاحظة المهارات البيائية.

r- الطلاب: من خلال دراستهم لقائمتى المعارف والمهارات البيئية المرتبطة بتخصصهم.

\section{هضوض التراسلة}

\section{يقتصر تطبيق الدراسة على الحدود الآتية:}

1- الحدود البشرية: سوف يتم تطبيق الدراسة على مجموعة من الطلاب بالصف الثانى

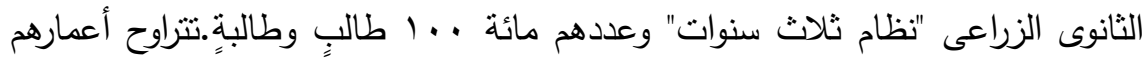

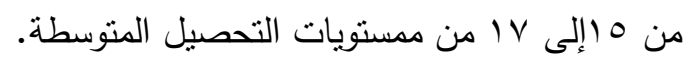
r- الحدود الزمنية: تم تطبيق هذه الدراسة فى الفصل الدراسى الثانى من العام الدراسى: 10

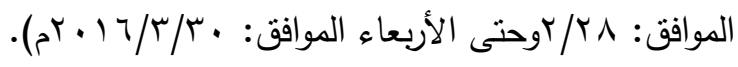

r- الحدود المكانية: نم تطبيق الدراسة بمدرستين، الأولى: مدرسة مشتهر الثانوية الزراعية

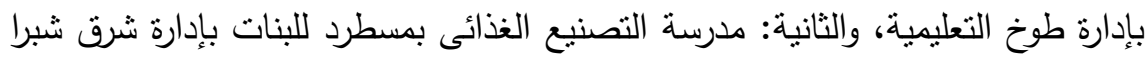
الخيمة التعليمية، والمدرستان بمحافظة القليوبية. 


\section{هنوضر التراسلة}

فى ضوء مشكلة الدراسة وتساؤلاتها بسعى الباحث للتحقق من صحة الفروض الثالية:

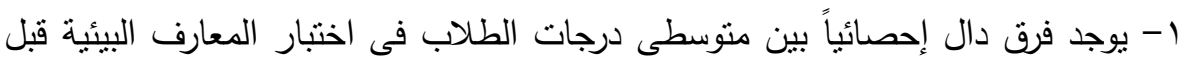
وبعد نطبيق البرنامج لصالح التطبيق البعدى.

r- يوجد فرق دال إحصائياً بين منوسطى درجات الطلاب فى بطاقة ملاحظة المهارات

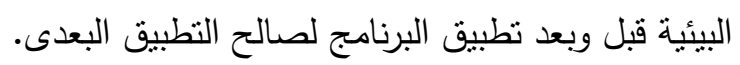

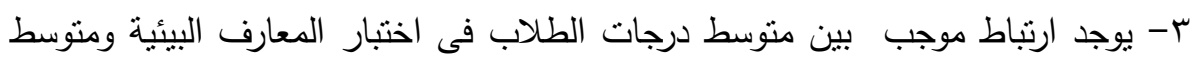
درجاتهم فى بطاقة ملاحظة المهارات البيئية فى التطبيق البعدى.

\section{هنهمج التواسم}

استخدم الباحثون المنهج شبه التجريبى ذا التطبيق القبلى والبعدى لتطبيق البرنامج

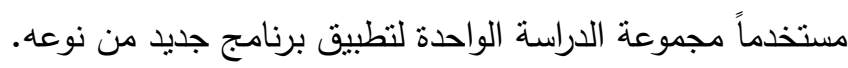

\section{إجزاءاهي التراسما}

أولاً: الاراسة النظرية:

ا - الرجوع إلى الدراسات العربية والأجنبية المرتبطة بموضوع الدراسة بشقيه المعارف البيئية والمهارات البيئية.

r- مراجعة الدراسات والبحوث السابقة التى تتاولت التصنيع الغذائى والصناعات الغذائية. r- مسح شامل للمراجع التى تتاولت المعارف البيئية والمهارات البيئية والمراجع التى تتاولت التصنيع الغذائى والكتب المقررة بالمدارس الثانوية الزراعية بقسم التصنيع الغذائى. r- استطلاع آراء المتخصصين فى التربية البيئية والزراعة البيئية والمناهج وطرق التدريس. ع- حصر أهداف مقررات الطلاب بقسم التصنيع الغذائى بالمدارس الثانوية الزراعية. 
ثانياً: الدراسة الميدانية:

() عرض القائمة المبدئية لكل من المعارف والمهارات البيئية على المحكمين المختصين

$$
\text { لإعدادها فى صورتها النهائية. }
$$

r) تحليل محتوى بعض الكتب المقررة على طلاب المدارس الثانوية الزراعية بقسم التصنيع الغذائى فى ضوء شقى موضوع الدراسة.

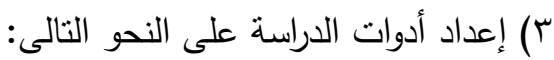
أ- إعداد كتاب الطالب ودليل المعلم وإعداد اختبار المعارف التحصيلى وعرضه على لـى مجموعة الخبراء والمتخصصين والتجربة الاسنطلاعية لحساب صدقه وثباته. ب- إعداد بطاقة ملاحظة المهارات البيئية لتحديد مدى اكتساب الطلاب لهذه المهارات. ج- تحديد العينة العشوائية لمجموعة الدراسة والتأكل من تكافؤ أفراد المجموعة. د- إعداد اختبار تحصيلى للمعارف البيئية المرنبطة بالتصنيع الغذائى. هـ - تدريس البرنامج المقترح لهجموعة الدراسة.

ز - تطبيق كل من اختبار المعارف وبطاقة الملاحظة قبل وبعد تدريس البرنامج المقترح. ح- تفريغ الدرجات، ومعالجتها إحصائياً فى ضوء التحقق من صحة الفروض ورصد النتائج وتحليلها ومناقتشتها وتفسيرها.

ط - تقديم مجموعة من التوصيات والمقترحات فى ضوء ما توصلت إليه نتائج الدراسة.

\section{همطلحايت الصراسمة}

البرنامـ Programme: البرنامج هو مجموعة الوحدات المخططة والمترابطة التى تهدف إلى تتمية مجموعة من المعارف والمهارات البيئية المرتبطة بمجال التصنيع الغذائى. المعارف البيئية:Environmental knowledge: هى:"ما يتحصل عليه التلاميذ من معارف ومعلومات بيئية نتيجة مشاركتهم الفعلية فى القيام بالأنشطة المدرسية

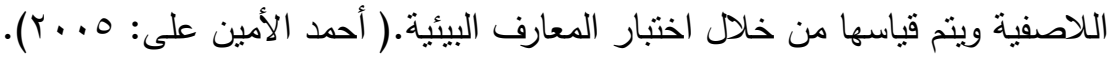


المهارات البيئية:Environmental skills: هى: "القيام بعمل محدد (عقلي أو بدني) مرتبط بالبيئة في أقل وقت وجهذ مع ثلافي أضراره وأخطاره السابقة بقدر الإمكان".

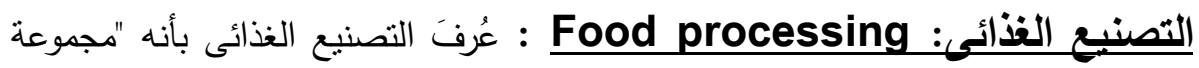

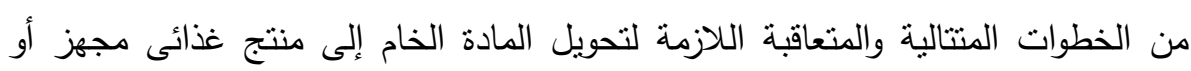
مصنع نهائى، وصالح للاستهلاك الآدمى".(فريدة بسيونى: 99 (1) ). وفيما يلى استعراض أهم الدراسات التى تعرضت للمعارف، والدئي الدهارات البيئية والتصنيع

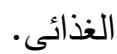

\section{التراسايت الماريهن}

دراسات المحور الأول: دراسات اهتمت بالتصنيع الغذائى والصناعات الغذائية

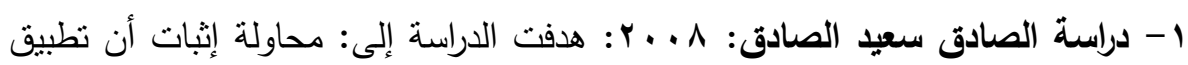

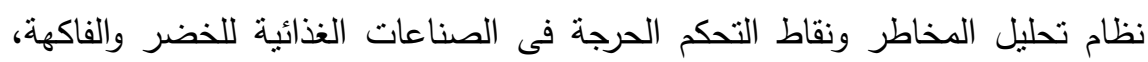

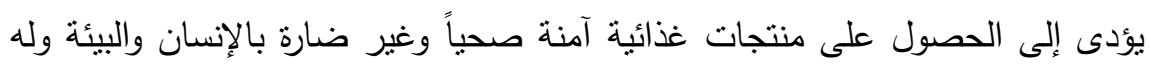

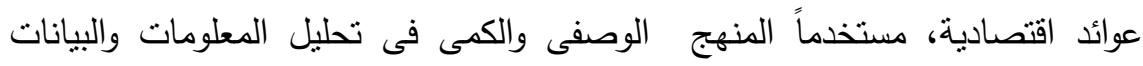

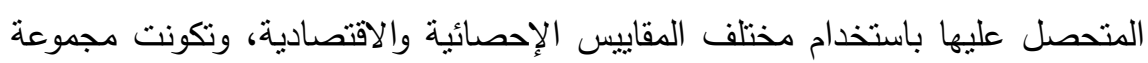
الدراسة من عشر · ل1 شركات فى قطاع الصناعات الغذائية، وقد استخدم الباحث فى الإنى

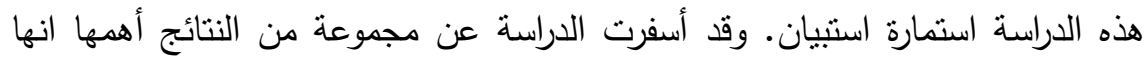
كثفت عيوب ومميزات نظام تطبيق المخاطر ، ونقاط النحكم الحرجة على الصناعات الثرات

$$
\text { الغذائية للخضر والفاكهة فى مصرب }
$$

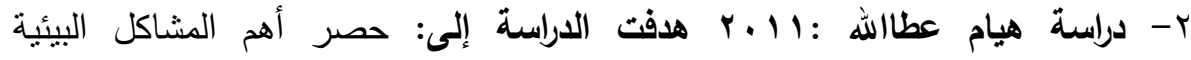

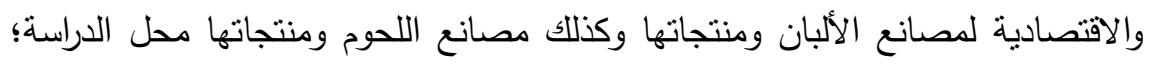

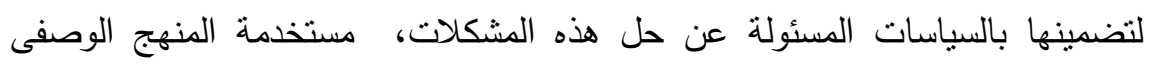

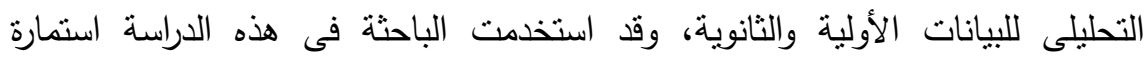

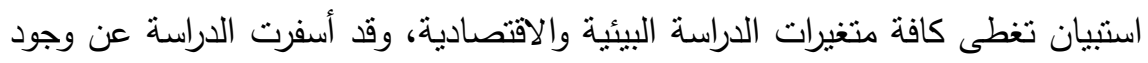

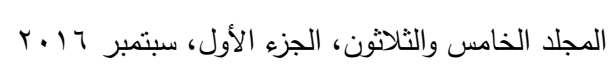


علاقة طردية بين نجاح الثركة الاقتصادية وبين العوامل البيئية والاجتماعية المرتبطة بها والخاصة بالمبحوثين.

\section{دراسات المحور الثانى: دراسات اهتمت بالمعارف والمهارات البيئية:}

1- دراسة إيمان صالح العباسى9 . . ب : هدفت الدراسة إلى بيان فاعلية استخدام المدخل

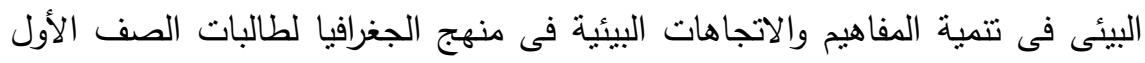

المتوسط فى المملكة العربية السعودية، وقد استخدت الباحثة الأدوات البحثية التالية:- اختبار المفاهيم البيئية، مقياس الاتجاهات البيئية. وقد أسفرت الدراسة عن وجود فرق

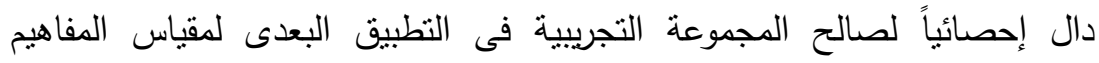
البيئية، ولمقياس الاتجاهات البيئية. كما كثنفت عن وجود علاقة دالة إحصائياً بين تحصيل المفاهيم البيئية واكتساب الاتجاهات البيئية لدى طالبات المجموعة

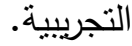

r - دراسة مريم محمود مصطفى 9 . . ץ: هدفت الدراسة إلى: تحديد فاعلية برنامج مقترح فى السياحة البيئية لتتمية المعارف والاتجاهات البيئية لدى طلاب أقسام السياحة بمعاهد التعليم العالى، وقد استخدم الباحثة الأدوات البحثية: اختبار معرفى، مقياس للاتجاهات البيئية. وذلك لتقييم الجانب المعرفى والوجدانى لطلاب شعبة الدراسات والسياحة البيئية بمعاهد التعليم العالى. وقد أسفرت الدراسة عن: اكتساب طلاب المجموعة التجريبية لمعارف واتجاهات بيئية لم يكتسبها طلاب المجموعة الضابطة، كما لهاب أثنتت الدراسة تأثر طلاب العينة بالأنشطة التعليمية والزيارات الميدانية التى قاموا بها

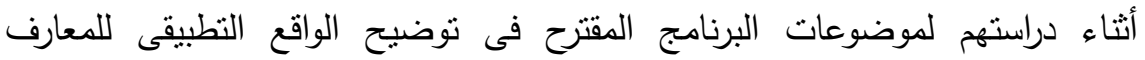
والاتجاهات البيئية. r- دراسة محمد عبد العزيز r ا ـ . ץ: هدفت الدراسة إلى: إعداد برنامج فى التربية البيئية تتمية المفاهيم والاتجاهات البيئية لطلاب المرحلة الثانوية التجارية، وقد استخدم الباحث المنهج الوصفى التحليلى لإعداد الإطار النظرى والبرنامج المقترح والوحدة التجريبية وأدوات الدراسة، كما استخدم المنهج التجريبى للكثف عن فاعلية برنامج التربية البيئية 
فى نتمية المفاهيم والاتجاهات البيئية، وتكونت مجموعة الدراسة من أربعين •ــ طالباً من طلاب مدرسة السادات الثانوية التجارية التابعة لإدارة السنبلاوين التعليمية بالدقهلية،

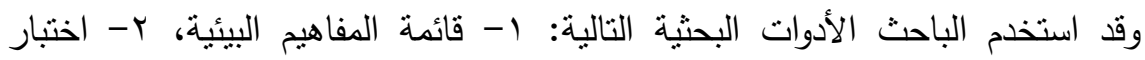
المفاهيم البيئية. ب- مقياس الاتجاهات البيئية. وقد أسفرت الدراسة عن النتائج التالية:

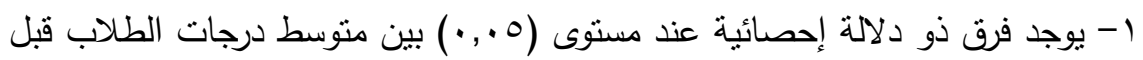

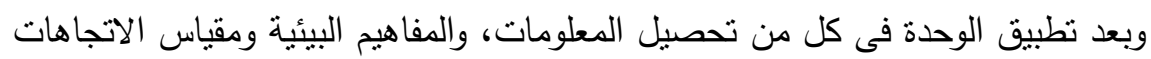

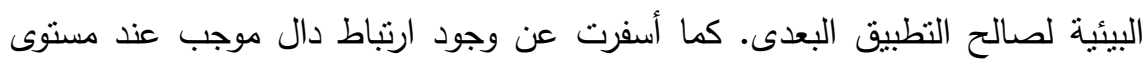
(0., •) بين درجات الطلاب فى كل من اختبار المفاهيم البيئية ومقياس الاتجاهات البيئية. وقد أظهرت النتائج أن البرنامج المقترح ذو فئ فاعلية فى تحصيل الطلاب

$$
\text { اللمعلومات والمفاهيم البيئية. }
$$

دراسات المحور الثالث: دراسات اهتمت بيناء برامج ووحدات بالمناهج

التعليمبة:

1- دراسة نور الدين أحمد عطية ^ . . ץ: هدفت الدراسة إلى تحديد فاعلية برنامج لتتمية المسئولية البيئية لدى طلاب مرحلة الثانوية العامة فى محافظة شمال سيناء، وقد تمثلت

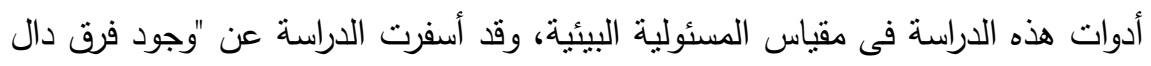

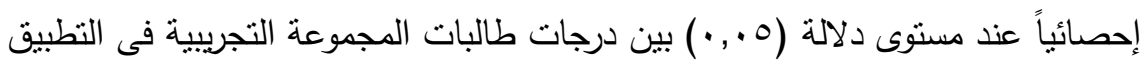

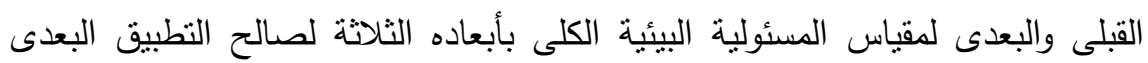
بالنسبة: لبعد فهم المعارف البيئية، وبعد السلوك البيئى المسئول، وبعد الاتجاه نحوالبيئة، لئه لئه

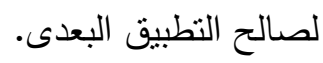

r - دراسة هند يوسف حسين 9 9 . ب: هدفت الدراسة إلى تحديد فاعلية برنامج لتتمية

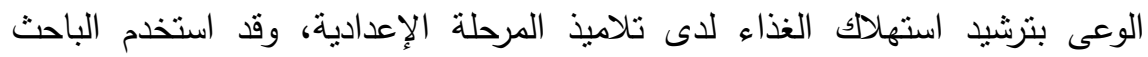

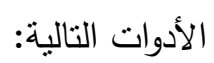

1- اختبار تحصيلى للتعرف على محقة البرنامج من ثقافة غذائية لدى التلاميذ عينة الدراسة. 
r- مقياس الاتجاهات البيئية نحو بعض القضايا المتعلقة بالغذاء.

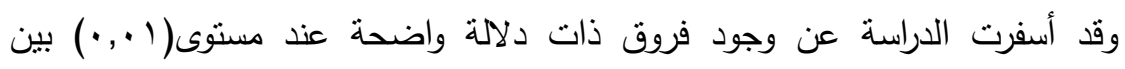

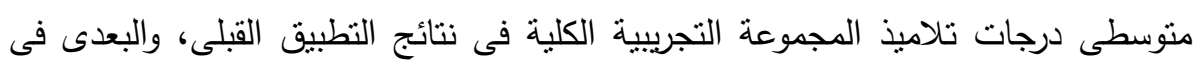
اختبار التحصيل ومقياس الاتجاهات، وذلك لصالح درجات التطبيق البعدى. كما أسفرت

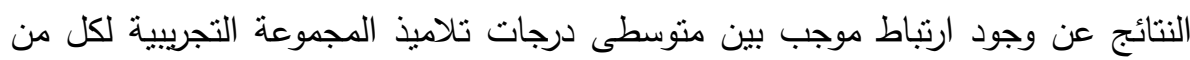
الاختبار التحصيلى ومقياس الاتجاهات البيئية نحو بعض القضايا المتعلقة بالغذاء. r- دراسة إنجى صلاح | 1 ـ ب : هدفت الدراسة إلى: بناء وحدة مقترحة قائمة على المواطنة البيئية فى تدريس الدراسات الاجتماعية لتتمية القيم البيئية لدى طلاب المرحلة الإعدادية،

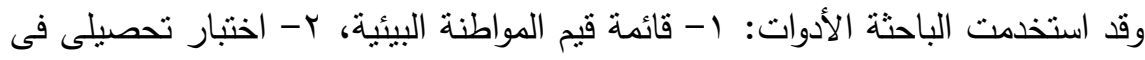

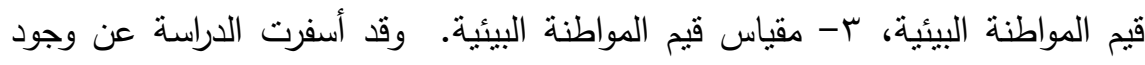
فروق دالة إحصائياً بين متوسطات المجموعتين الضابطة والتجريبية فى القياس البعدى التى لكل من مقياس قيم المواطنة البيئية ككل، وكل قيمة من قيم المواطنة لطلاب المرحلة الإعدادية لصالح المجموعة التجريبية.

\section{تعقيب على الدراسات السابقة: تباينت الدراسات والبحوث السابقة من حيث:} 1 - اختبار التصميم التجريبى؛حيث إن بعض هذه الدراسات والبحوث اختارت عينة الدراسة من مجموعة واحدة تجريبية وهو ما اتبعته وفرضته طبيعة الدراسة الحالية، بينما اختارت لتهن بعض البحوث الأخرى لعينة الدراسة مجموعتين متكافئتين إحداهما ضابطة والأخرى

r- تباين المراحل التعليمية التى تم تطبيق الدراسات السابقة عليها وبالتالى اختلاف المستويات والأعمار إلا أنه لم يستخدم المرحلة الثانوية الزراعية إلا عدد قليل جداً.

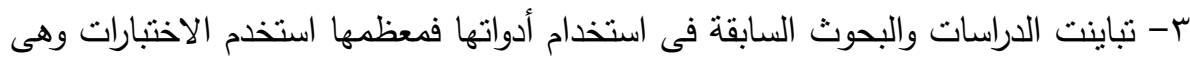
فى الغالب لقياس المفاهيم والمعارف، ومقاييس الاتجاهات والمهارات وهو ما استخدمته

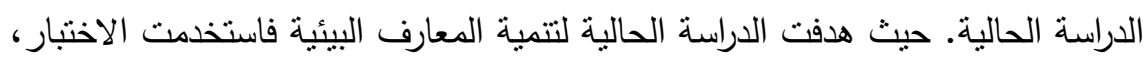
كما استخدمت لقياس المهارات البيئية بطاقة ملاحظة المهارات البيئية. 
وقد استفادت الاراسة الحالية من مجموعة الدراسات السابقة فى هذا المحور ما يلى:

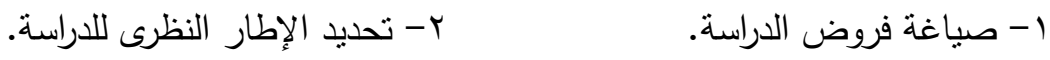
r- التعرف على الخطوات التى تتبع فى بناء البرنامج المقترح للاراسة الحالية، وإعداد الإطار العام لمحتوى البرنامج المقترح، وإعداد الوحدة التجريبية محل الدراسة. ع - اختيار التصميم التجريبى المناسب. - اختيار الأساليب الإحصائية المناسبة للاراسة.

\section{الإسار المعرهى للدراسة}

المحورالأول: التعليم الفنى الزراعى الإسار

أهداف التعليم الزراعى: كان هذا التعليم بيتهدف الارتقاء بالإعداد العام لطلابه عقلياً وبدنياً

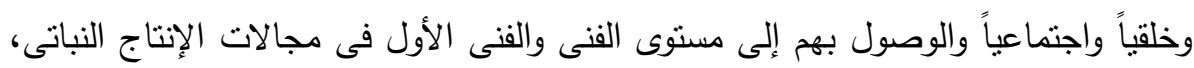

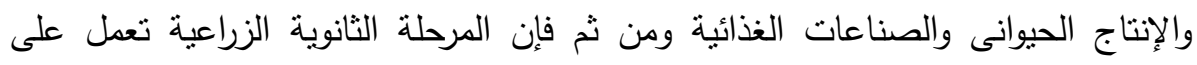
إعداد فئات من الزراعيين الذين يتوافر لديهم القدر المناسب من التقافة العامة والزراعية

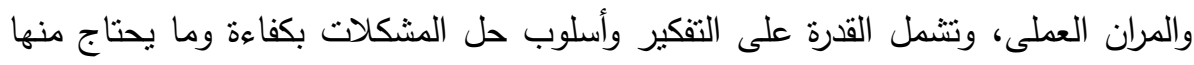
إلى مهارة فى تفسير الإحصاءات والبيانات وتتمية اتجاهات واهتمامات مرغوب فيها وإبراز

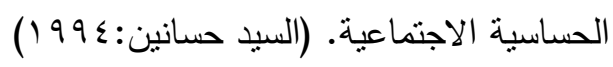

العلاقة بين الزراعة والبيئة: زادت مساهمة الزراعة المكثفة فى تفاقم المشكلات البيئية سواء

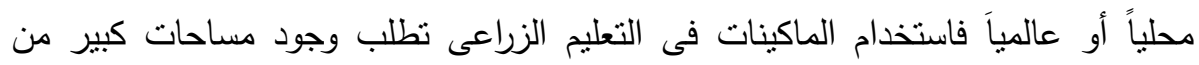

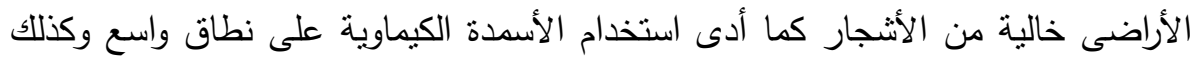

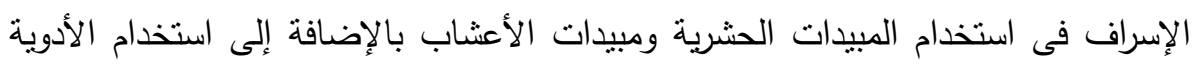
البيطرية إلى تلوث الأغذية وترتب على هذا التلوث مشكلات صحية كبيرة، ومن هنا تبدو

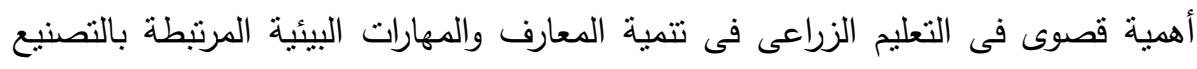

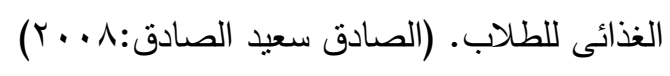

المحور الثانى:التصنيع الغذائى: والهدف الرئيس لتصنيع الأغذية هو حفظها وإمكانية نقلها إلى أسواق بعيدة وتخزينها واستهلاكها على مدار السنة كما يجعل التصنيع الغذائى

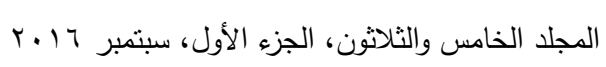


أكثر ملائمة للطبخ وأسهل فى التحضير وهذا ما يفسر الثعبية المتزايدة للاغذية المعلبة

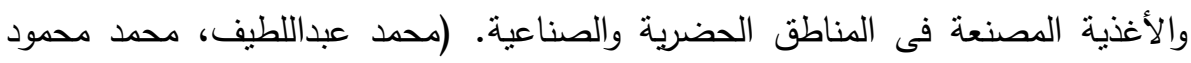

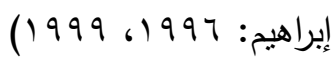

الصناعات الغذائية والحفاظ على البيئة: منذ بدء الخليقة كانت الصناعات الغذائية من أوائل

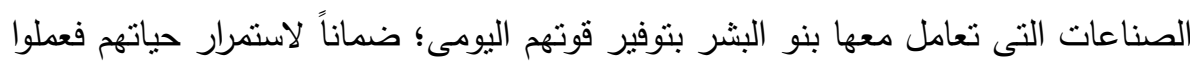

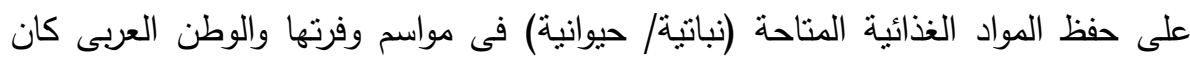

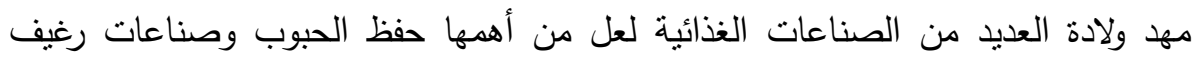

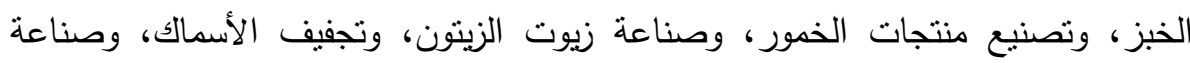

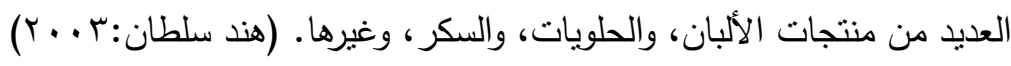
وبحكم الظروف الاقتصادية لثريحة واسعة من المواطنين تجد الصناعات الغذائية المنتجة حرفية أو ضمن المصانع الصغيرة رواجاً؛ نظراً لتندى أسعارها فى عديد من الأسواق

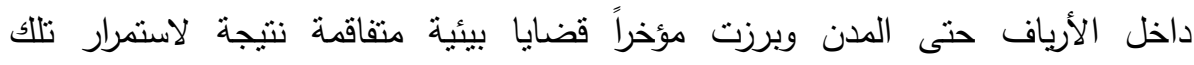

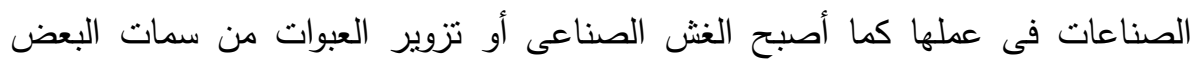
منها، وفى حين أولت الحكومات العربية (الجهات المسئولة عن الصناعات الغذائية) اهتماماً

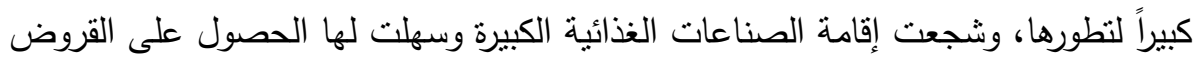

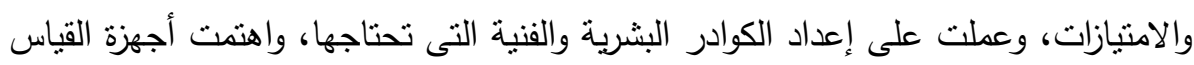

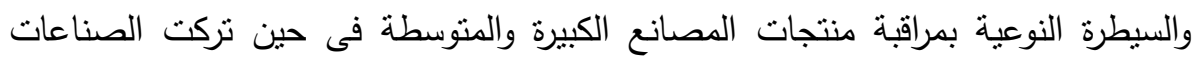
الغذائية الحرفية والصغيرة دون إعطائها العناية التى تنتحقها رغم أن تأثثرها يعم على تئى شريحة واسعة من المستهلكين.

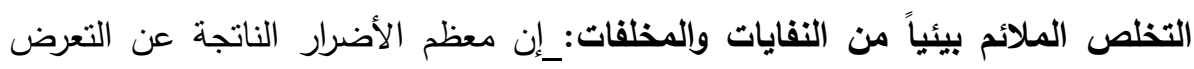

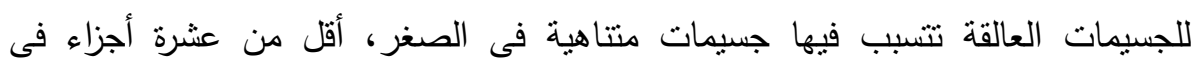
المليون وتخترق هذه الجسيمات طريقها حتى تصل إلى الرئة مسببة أعراض مرضية مختلفة

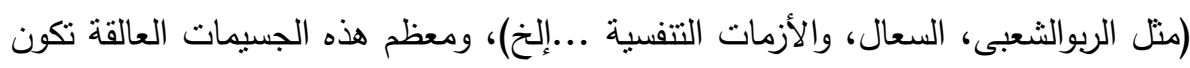


ناتجة عن عمليات الإحتراق الغير تام ومن أمثلتها : الرماد ، السناج، أوالمركبات الكربونية،

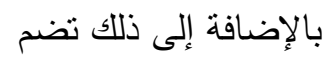
الجسيمات العالقة منكثقات حمضية، ومعادن مثل: الرصاص، والكادميود، وكبريتات،

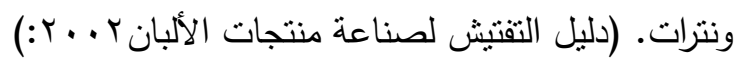
التلوث أثناء مرحلة التصنيع: أصبح التصنيع الغذائى ضرورة ملحة للحفاظ على الفاقد من الأغذية، ولتعظيم الاستفادة من المنتجات النباتية، والحيوانية، ويجب أن براعي فئه في عملية

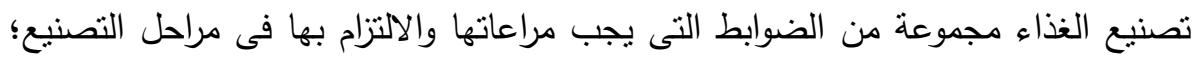
منعا للنلوث الغذائي. فمثلا لابد أن تكون المياه المستخدمة في الصناعات الغيط الغذائية مطابقة

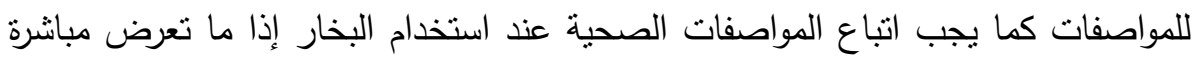

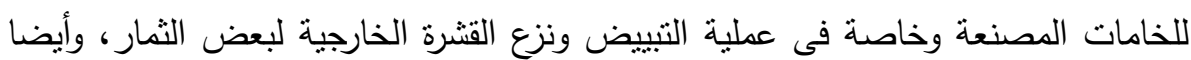
فى عملية التعقيم ، حيث ثبت أن البخار يمكن أن يكون مصدرا للتلوث نتيجة مروره فى لئه

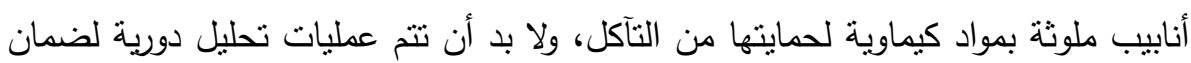

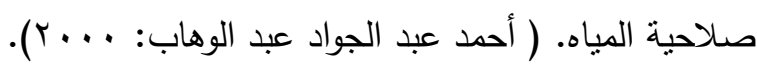

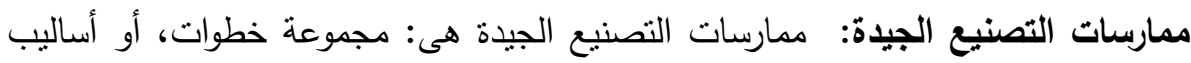

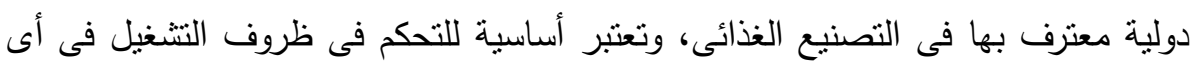

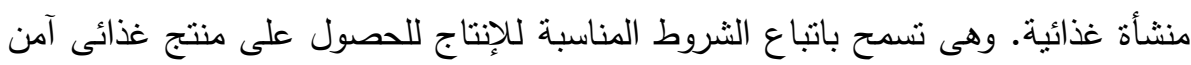

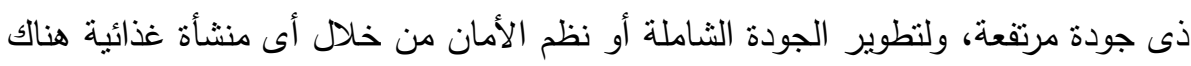

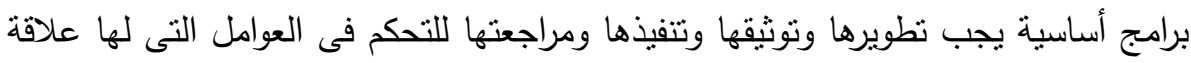

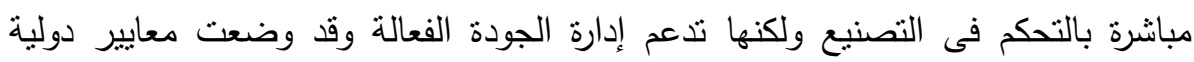
عديدة لمنطلبات ممارسات التصنيع الجيدة والتى وزعت على أساس المنطلبات القانونية ومواصفات العملاء. 


\section{المحور الثالث: المفاهيم والمهارات البيئية:

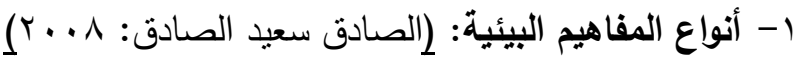
أ) مفاهيم عبارة عن تصنيفات من الأثياء أو الأحداث التى تهذف إلى الوصف وتسهيل

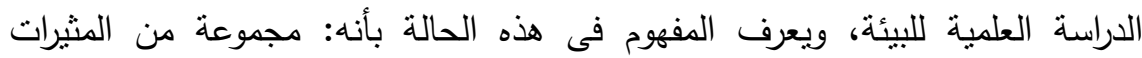
تجمعها صفات مشتركة.

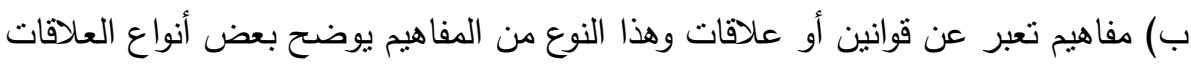

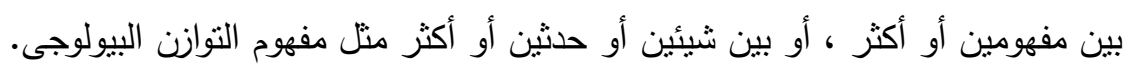

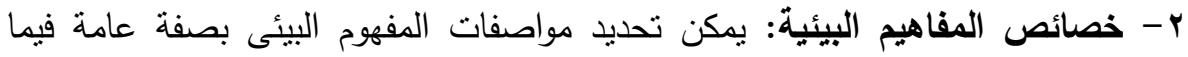

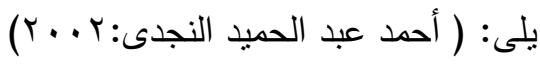
أ) يختلف الدفهوم من شخص لآخر حسب السن والخبرة. ب) قد يتضمن المفهوم الواحد مجموعة مفاهيم متفرعة منه. ج) قد يكون الدفوم فى منتهى البساطة والسطحية، وقد يكون غاية في العقى والتعقيد.

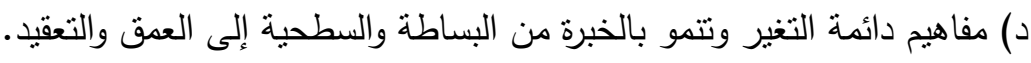

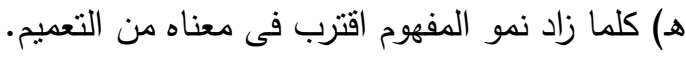

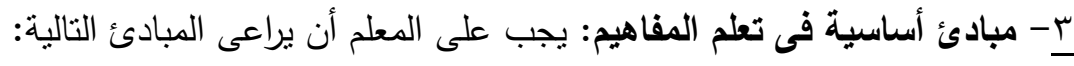

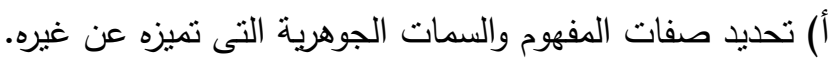
ب) تحديد القاعدة التى تنظم هذه السمات فى إطارها.

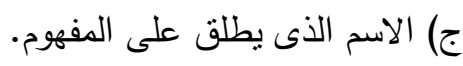

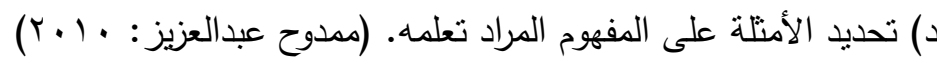

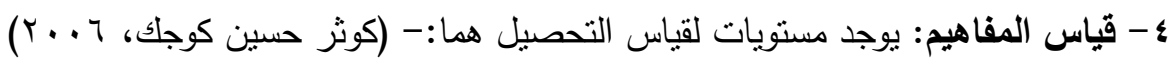

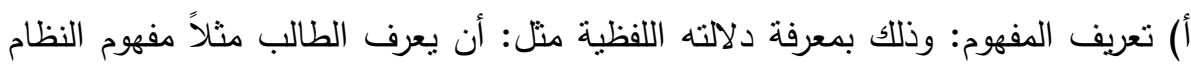
البيئى.

ب) قياس مدى الدفهوم: أى القدرة على استخدامه فى مواقف جديدة أو بمعنى آخر الاستخلال على تحصيل المتعلم للمفهوم وذلك يتضح من خلال: 
- التعبير اللفظى للتعبير عن المفهوم وما تعنيه دلالته اللفظية. - أن يميز المتعلم بين الأثياء والظواهر ويصنفها بما يندرج أولا يندرج تحت طائفة المفهوم. - قدرة المتعلم على توظيف المفاهيم أى استخدامها فى مواقف جديدة.

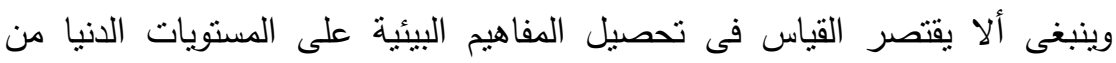
القياس كمستوى التعريف اللفظى للمفهوم، ولكن يجب مراعاة المستويات العليا من القياس كالتصنيف، والتمبيز، والتفسير، والمقارنة، والافتراض، والاستتناج، والتتبؤ - والتى تركز

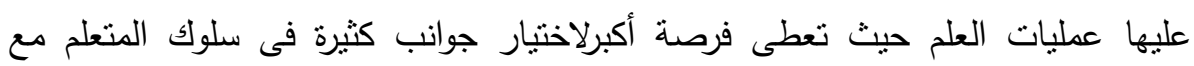
التذرج من البساطة إلى التعقيد، ومن السهولة إلى الصعوبة، ومن الحسى المادى إلى هرئى المعنوى المجرد. ثالثاً: المهارات البيئية:

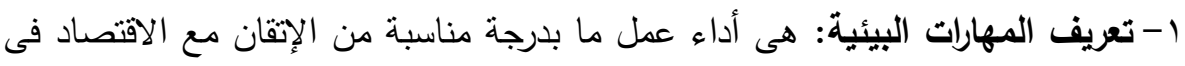

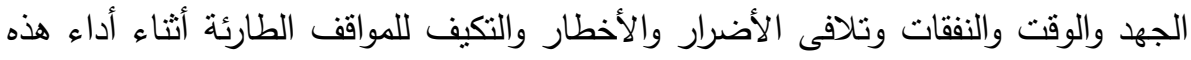

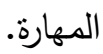
بينما تعرف المهارات البيئية: أنها: قدرة الفرد على أداء الواجبات البيئية المنوط بها وحل المشكلات البيئية التى نواجهه بما تحتاجه من قدرات عقلية أو يدوية بأعلى كفاءة ممكنة

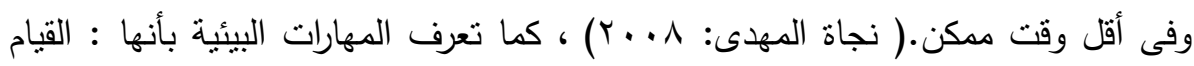

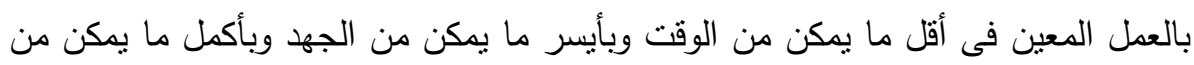

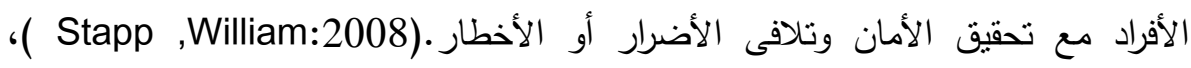
وبالنسبه للمهارات البيئية فإن عملية إكساب مهارات حل المشكلات وتتميتها تعتبر ضرورية الاضران

r- أنواع المهارات البيئية: قام "Sund and Ttrowbridge " بتصنيف المهارات فى الأنواع الخمسة الآتية وتتضمن كل منها مهارات فرعية على النحو التالى:1- مهارات الاكتساب ومنها: الملاحظة - جمع البيانات.

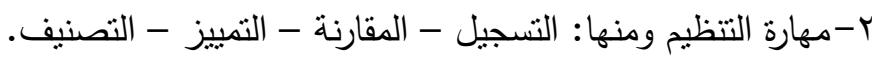




$$
\text { ع-مهارات التناول ومنها: استخدام الأدوات - العناية بالأدوات - العرض. }
$$

وأيضاً من المحاولات المتعددة لتصنيف الميدان النفسركى تصنيف (Zais) حيث قسم الميدان النفسحركى إلى أربعة مستويات تصاعدية لمعالجة المهارات وهذه المستويات

أ) الملاحظة: أى الانتباه إلى آداء أكثر خبرة.

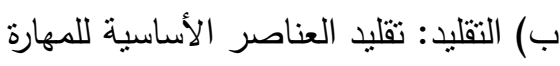
ج) الممارسة: يقصد بها التمرين على طريق التكرار وتتابع عناصر المهارة مع تقليل الجهد المبذول فى الأداء تدريجياً. د) الإتقان: إتقان المهارة مع احتمال زيادة هذا الإتقان.

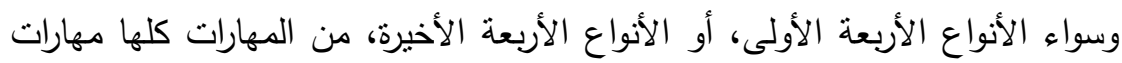

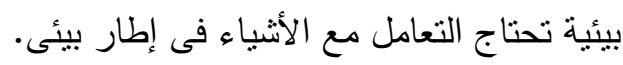
r- شروط المهارات البيئية: يتطلب إتقان المهارة شرطين أساسيين: أ) معرفة الأساس النظرى للمهارة: أى معرفة خطوات العمل وخطوات الإجراءات.

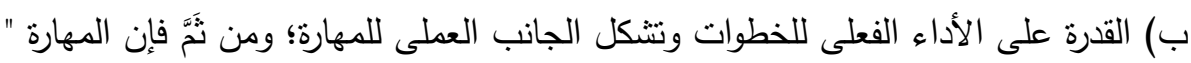
أنماط من السلوك تستدعى معرفة نظرية وقدرة على الفعل وعمليات تتسيقية". ع - تنمية المهارة البيئية لاى الطلاب: هناك استراتيجية بمكن أن تستخدم لنتمية المهارات البيئية وتتمل المراحل الخمسة الآتية:

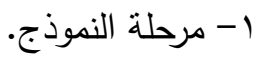
r- برحلة النطبيق أوالتدريب مع المساعدة. r- مرحلة التدريب أو التطبيق بعد المراجعة. ع- مرحلة الأداء المستقبل. - مرحلة الإبداع. 
صابر محمود حسين وآخرون

\section{خطوايت الترواسلة}

للإجابة على الأسئلة البحثية للاراسة اتبع الباحث مجموعة الخطوات التالية:

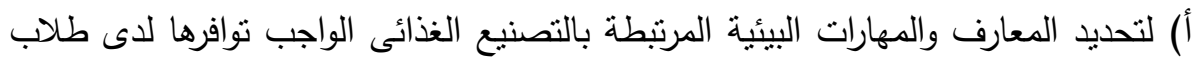
المدارس الثانوية الزراعية وهذا تضمن:

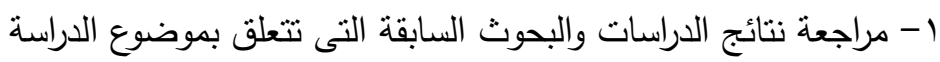
r- استطلاع رأى الخبراء والمتخصصهين. r- إعداد قائمة بالمعارف والمهارات البيئية المرتبطة بالتصنيع الغذائى الواجب توافرها لدى ولى طلاب المدارس الثانوية الزراعية وعرضها على مجموعة من المحكمين والخبراء المتخصصين فى المجال البيئى ومجال علوم الأغذية لمراجعتها وضبطها. 
قائمة المعارف البيئية المرتبطة بالتصنيع الغذائى والواجب توافرها لاى طلاب المدارس الثانوية الزراعية بقسم التصنيع الغذائى لئى

\begin{tabular}{|c|c|c|c|c|c|}
\hline أشعازت & 2 & المعارن & 2 & أمعارئ & 2 \\
\hline كُطهر الأغنبة & 19 & 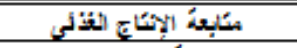 & ro & 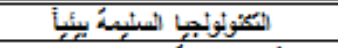 & 1 \\
\hline 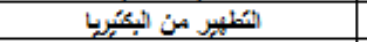 & $v \cdot$ & 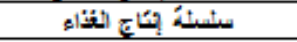 & +4 & 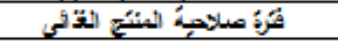 & $r$ \\
\hline تشيط المبكرب & $v_{1}$ & 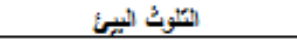 & $r v$ & 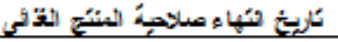 & $r$ \\
\hline نئبط بكابري & $\mathrm{Vr}$ & انكتوبُ3 الآنشى & $r \mu$ & المصنب الغت ني & $\leq$ \\
\hline مقازوبة المأكسذ & $\mathrm{VT}$ & 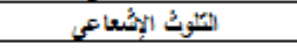 & +4 & 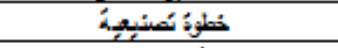 & 0 \\
\hline المرئبة الصمية & $v \leqslant$ & 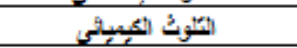 & $\leq$ & معاربة التصنبي الجي & $\checkmark$ \\
\hline التوزيز المسطحي & vo & 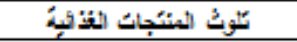 & $\leqslant$ & مسدر التصنبي (خريطة المسلر) & $v$ \\
\hline 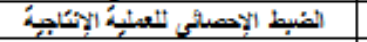 & $\mathrm{Vi}$ & تلويُ3 الماء & $\leqslant$ & مخلثات تصني الئاء وستهلاكي & $\wedge$ \\
\hline المطرث المرئزي لبكئريا & $\mathrm{VV}$ & تلتوق القرية & $\leqslant$ & مخثات إنكاع الغتاء & 4 \\
\hline إعادةُ التشوبر & $\mathrm{vA}$ & تكوتك عزضبر & $\leq \leqslant$ & الصناعات الثتئة الصفُرة & 1. \\
\hline 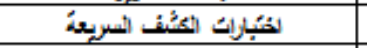 & $\mathrm{V4}$ & 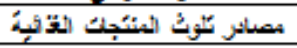 & $\leqslant 0$ & الاعشياد: Accreditation & $\cdots$ \\
\hline 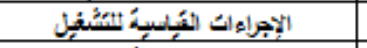 & A. & فُساد الأتخبة & $\leqslant$ & 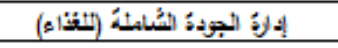 & 14 \\
\hline 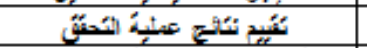 & AI & يُّكثة: المستوحة & $\leqslant v$ & الجوثة الغتاه & it \\
\hline 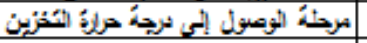 & $\Delta \Lambda^{+}$ & كُشد التخاء & $\leqslant \wedge$ & 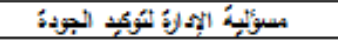 & 15 \\
\hline 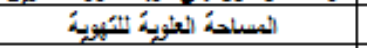 & AT & 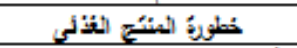 & $\leqslant 4$ & 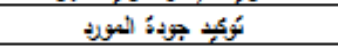 & 10 \\
\hline مبكزب شهرض & $A \leqslant$ & 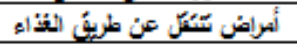 & 2. & خطة الجزدة: & 15 \\
\hline نفائبة المروئع & Ao & مصنائر الخفر & 21 & 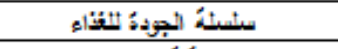 & iv \\
\hline الأخزيست & 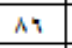 & تحبل المخاطر & or & مرائَّة الجزوبة & 11 \\
\hline 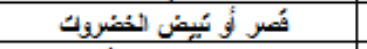 & AV & 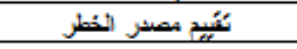 & or & نقلا توكبد الجزئً & 19 \\
\hline 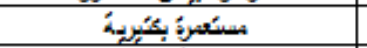 & $\mathrm{AA}$ & قصالات المخاطز & $0 \leq$ & مراجعة الجوئً & $r+$ \\
\hline صدلأهة الهباسب & 19 & يخاطرالثتاء & 20 & أُسان التخاء & +1 \\
\hline خطة الهباسب & 9. & إبالة لبخاطر & 24 & غُاء آتن & ri \\
\hline 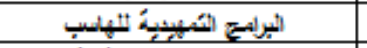 & 41 & الخطر النبيؤيجي & ov & سلاغة الئاء & TT \\
\hline برائيح المتطلثبات الأولثية & 94 & أخفطر الطفيعى & 21 & 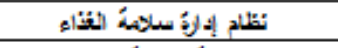 & $r \leq$ \\
\hline الإجراء التصبحيحي & $4 \pi$ & الخطر الكيبيأي & 24 & سباسنة سلاهة الفتاه & io \\
\hline 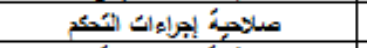 & 4 4 & 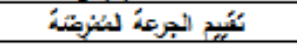 & $\checkmark$. & 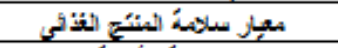 & $r$ \\
\hline نأفلة كَكم حرجة & 40 & حنظ المتاه & $\because 1$ & 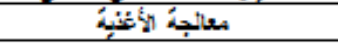 & TV \\
\hline 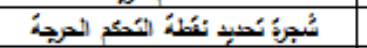 & 49 & المواء الشضاقة & $i r$ & مواعنات الأغخبة & rA \\
\hline كتُرل الحمك & $9 \mathrm{~V}$ & 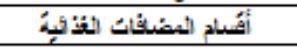 & it & التصعَِّّد & 19 \\
\hline 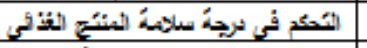 & 91 & المواد الحافتأة & $7 \leq$ & 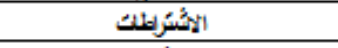 & $r$. \\
\hline 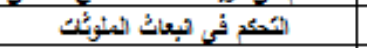 & 94 & المواد المقعة لنأكسيةً & 10 & ملائسة الفتاء & $r 1$ \\
\hline الإحتمرافت عن حثون نئطة الحمك & $\cdots$ & أمنكيات المنتُقطة & 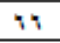 & 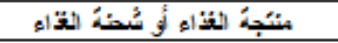 & $r+$ \\
\hline \multirow[t]{2}{*}{ 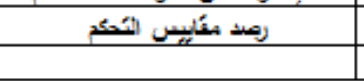 } & $1+1$ & 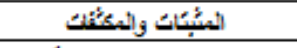 & iv & طرئَ حنظ المنتجاك الفتبة & 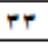 \\
\hline & & مكسبات الطعد والريحة. & $\checkmark \wedge$ & مخثناك المنتجاك الثتنة & $r \leq$ \\
\hline
\end{tabular}


ع - مراجعة مناهج طلاب التعليم الزراعى بقسم التصنيع الغذائى من حيث أهداف وحداتها

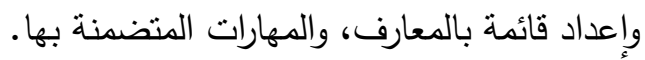
ه- تحليل الكتب والمراجع ذات الصلة بمناهج هؤلاء الطلاب من حيث المعارف البيئية المتوفرة بها فى ضوء قائمة المعارف البيئية التى نم التوصل إليها. ثبات نتائج تحليل المقرات بقسم التصنيع الغذائى على طلاب المدارس ث ثلئه الزراعية

\begin{tabular}{|c|c|c|}
\hline نسبة الاتفاق & \multicolumn{2}{|c|}{ عدد المعارف التى تم التوصل إليها } \\
\hline & التحليل الثانى & التحليل الأول \\
\hline$\% \wedge 0, r q$ & $r \varepsilon$ & rq \\
\hline
\end{tabular}

7- مقارنة قائمة المعارف والمهارات البيئية المتضمنة بمناهج طلاب المدارس الثانوية

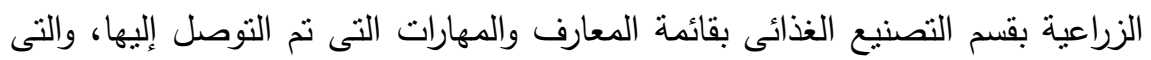
يجب أن نتوافر لدى هؤلاء الطلاب وجد تدى كبير فى مجموعة المعارف، والمهارات

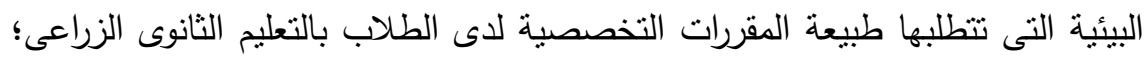

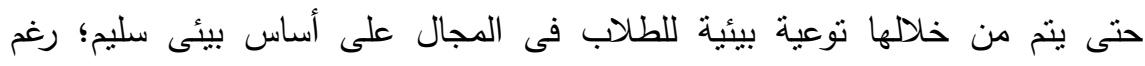
احتكاكهم المباشر بالعوامل البيئية المؤثرة على التصنيع الغذائى نطاق تخصصهم. خطوات بناء البرنامج المقترح: ولإعداد البرنامج المقترح لتتمية المعارف والمهارات البيئية المرتبطة بالتصنيع الغذائى لدى طلاب المرحلة الثانوية الزراعية وأدوات ثقويمه تضمن هذا اتباع خطوات بناء البرنامج التالية

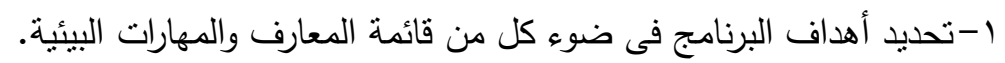
r-تحديد وتتظيم محتوى البرنامج. r- تحديد طرق التدريس المناسبة لتنفيذ البرنامج. ع - تحديد الأنشطة والوسائط التعليمية التى يتطلبها تتفيذ البرنامج. 0- تحديد أسئلة تقويمية لتقويم دروس البرنامج كل على حدة عقبط كل درس. צ- عرض البرنامج على مجموعة من الخبراء والمتخصصين لتعديله ومراجعته وضبطه. V- إعداد دليل المعلم للاسترشاد به فى تدريس البرنامج الذى تم التحكيم عليه. ا - أهداف البرنامجج: يهدف البرنامج المقترح إلى:

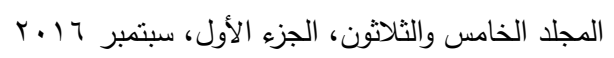


1- تتمية المعارف والمهارات البيئية المرتبطة بالتصنيع الغذائى لدى طلاب المدارس

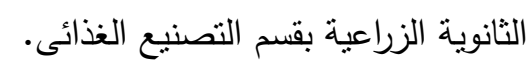
r- محتوى البرنامج: يتكون البرنامج من خمس وحدات دراسية وهذه الوحدات هى: 1- أساسيات التصنيع الغذائى والعوامل البيئية المؤثرة عليه. r- الممارسات الجيدة للتصنيع الغذائي (أسس وقواعد) r- الجودة فى التصنيع الغذائى. ع- تكنولوجيا التصنيع الغذائى

0- دراسة مستقبلية لإحدى طرق حفظ المنتجات الغذائية : التعبئة والتغليف. وكل وحدة تتكون من عدد من الدروس والجدول التالى يوضح هذه الوحدات، لغنهاته

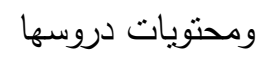
r- أساليب وطرق تدريس درونه البرنامج المقترح: نظراً لأن طرق التدريس تتكامل فيما بينها ويصعب استخدام أى منها فئ كل الموضوعات وفقاً لمحتوى وهدف كل موضوع خاصة ما يتعلق بالبيئة؛ لذا تم اختيار مجموعة من الطرق لتدريس موضوعات البرنامج حتى تحقق الهدف وهذه الطرق هى:-

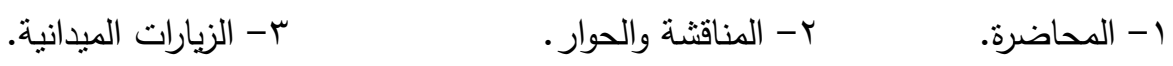
والجدول التالى يوضح الخطة الزمنية لتدريس موضوعات البرنامج، وطرق التدريس لكل منها: 
صابر محمود حسين وآخرون

الخطة الزمنية لتدريس البرنامج المقترح:

\begin{tabular}{|c|c|c|c|c|c|}
\hline المدرسة & التاريخ & اليوم & طرق التتريس & الموضوع عنوان & بوع \\
\hline مشتنهر ث الزذائعية للبنأثنين & $\begin{array}{l}r+1 T / r / r \wedge \\
\dot{r}+1 T / r / r\end{array}$ & الثنالثاء & \multirow{2}{*}{ المحاضرة، } & \multirow{2}{*}{ 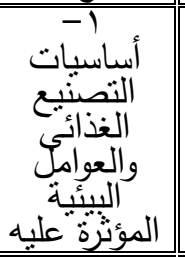 } & \multirow{2}{*}{ उ } \\
\hline 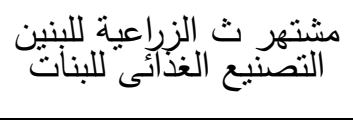 & $\begin{array}{l}r \cdot 1 T / r / r q \\
r \cdot 1 r-r / r\end{array}$ & الالإثبناء & & & \\
\hline 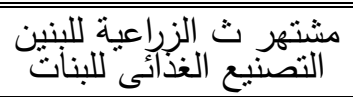 & $\begin{array}{l}.1 T / \Gamma / \mu \\
r .1 T / \mu / \Lambda\end{array}$ & الثالثاء & \multirow{2}{*}{ والمالحاقثنة } & \multirow{2}{*}{ 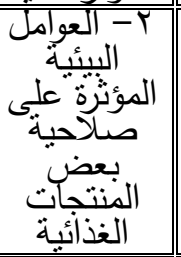 } & \multirow{2}{*}{ 芽 } \\
\hline مشتنهر ث الزيع الزي & $\begin{array}{l}r \cdot 1 T / r / v \\
r .1 T / r / 9\end{array}$ & الإلثتاء & & & \\
\hline 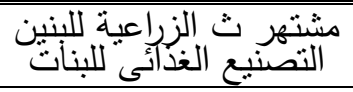 & $\begin{array}{l}+17 / r / 1 \\
r .17 / \mu / 10\end{array}$ & الثلاثاء & \multirow{2}{*}{ والرالحيارار، } & \multirow{2}{*}{ المَ-تلوثات } & \multirow{2}{*}{ 畿 } \\
\hline مشتهنيع ثال الت التصني & 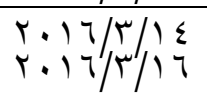 & الالإثتين & & & \\
\hline 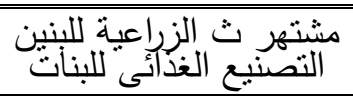 & 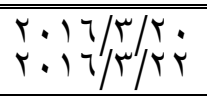 & الثلأحاء & \multirow[b]{2}{*}{ المحاضرة } & \multirow{2}{*}{ الالشتراطات البياتة } & \multirow[b]{2}{*}{$\overline{3}$} \\
\hline عية للبنأثنين & 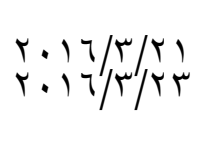 & الأربتثين & & & \\
\hline 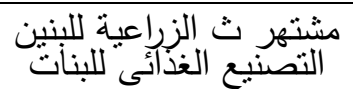 & $\begin{array}{l}r .1 T / \Gamma / r v \\
r .1 T / \Gamma / r q\end{array}$ & الألثاء & \multirow{2}{*}{ الإلزياراضيةتة } & \multirow{2}{*}{ الأغفظية } & \multirow{2}{*}{$\overline{.7}$} \\
\hline 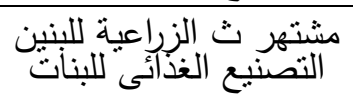 & $\begin{array}{l}r \cdot 1 T / \mu / r \wedge \\
r \cdot 1 \tau / \Gamma / \mu .\end{array}$ & الإبرباء & & & \\
\hline
\end{tabular}

ا- جمع المعلومات البيئية المتصلة بالتصنيع. ب- قراءات إضافية عن التصنيع

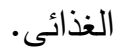

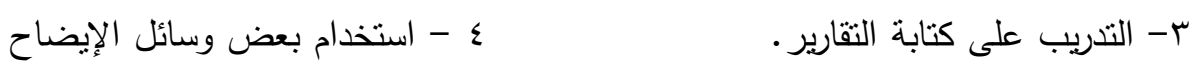

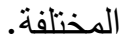

0- استخدام الحاسب الألى وشبكة المعلومات الأكترونية.

المجلد الخامس والثلاثون، الجزء الأول، سبتمبر 17 ب.

401 
צ- الزيارات الميدانية لمنشآت التصنيع الغذائى مثل زيارة إلى مصنع الأغذية بقرية قها-

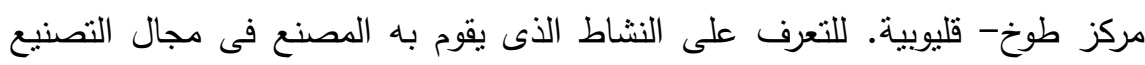

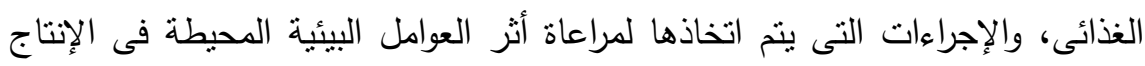
المختلفة، وممارسة الطلاب لهذه الأنشطة بحماس كبير ومواظبتهم على الحضور .

ه- - الوسائط التعليمية:

فيما يلى عرض لمجموعة من الوسائط التعليمية المصاحبة لتدريس البرنامج المقترح:

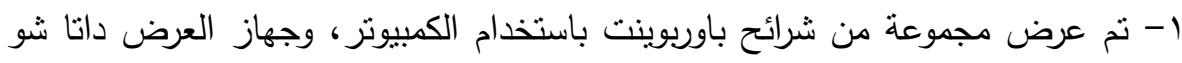
فى تدريس الموضوع الخامس (طرق الحفظ).

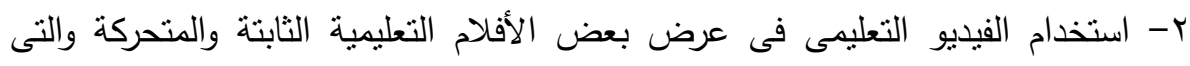
تعالج موضوعات بيئية منصلة بالبرنامج المقترح، وقد استخدم هذا الفيلم التعليمى فى الى الثى تدريس الموضوعين الأول والثانى والثالث: أساسيات التصنيع الغذائى والعوامل البيئية المؤثزة عليه، العوامل البيئية المؤثرة على صلاحية بعض المض المنتجات الغذائية، تلوث

$$
\text { المنتجات الغذائية وفسادها. }
$$
r- استخدام الأسطوانات المدمجة للحاسب الآلى (CD) وجهاز الحاسب الآلى فى تدريس الموضوع الرابع (الاشتراطات البيئية الصحية لسلامة المنتجات الغذائية).

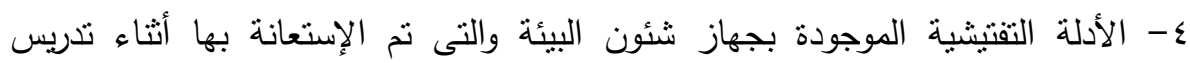

$$
\text { موضوعات البرنامج المقترح وهى: }
$$
• الدليل الإرشادى للتقانات الملائمة للصناعات الغذائية. • دليل التفتش لصناعة تجهيز الفواكه والخضراوات. دليل التفتيش لصناعة طحن الحبوب. دليل التفتيش لصناعة منتجات الألبان. دليل التفتيش لصناعة المشروبات الغازية. 
ه- استخدام الفيديو التعليمى فى عرض بعض الأفلام التعليمية الثابتة والمتحركة التى تعالج موضوعات بيئية متصلة بالبرنامج المقترح عن طريق استخدام الاسطوانات المدمجة للحاسب الآلى (CD) وجهاز الحاسب الآلى مثل: أفلام تعليمية تتعلق بالتلوث الغذائى، ومظاهره ، وأسبابه ، ووسائل الحد منه. • • صور فوتوغرافية لمسار حركة التصنيع الغذائى بأحد مصانع الأغذية. צ- تقويم البرنامج: نم تتفيذ عدة وسائل لتقويم البرنامج عبر مراحل تتفيذ البرنامج كما يلى بلى

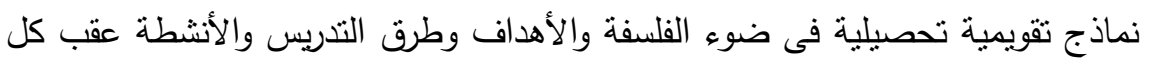
موضوع لقياس مدى تحصيله؛ وهو الذى يحدد مستوى الطلاب فى كل موضوع من موضوعاته الدراسية؛ لذا تم توجيه أسئلة محددة مناسبة لكل موضوع أثناء أنثاء الثرح لاستثارة الطلاب وإشراكهم فى الدرس بصورة حوارية وكذلك عقب الانتهاء من الدرس، وهناك أسئلة منزلية لتتافس الطلاب فى الإجابة عنها. • تصميم اختبار المعارف البيئية المرتبطة بالتصنيع الغذائى، وبطاقة ملاحظة المهارات التهاته

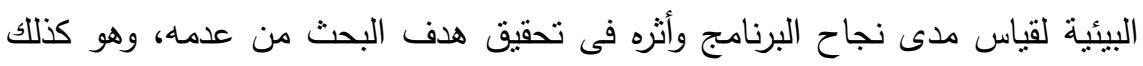

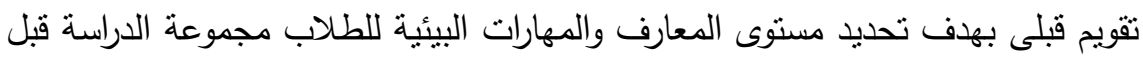

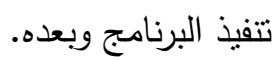
وحيث إنه توجد صعوبات تحول دون تطبيق البرنامج بأكمله فسوف يقتصر الأمر على تدريس إحدى وحداته؛ وهى الوحدة الأولى كمؤشر لتحقيق تتمية المعارف البيئية والمهارات البيئية لاى طلاب المدارس الثانوية الزراعية.

\section{أسوايت التوراسة}

استخدمت الدراسة الأدوات التالية من إعداد الباحثين: 1- اختبار تتمية المعارف البيئية المرتبطة بالتصنيع الغذائى لدى الطلاب. r- بطاقة ملاحظة المهارات البيئية المرتبطة بالتصنيع الغذائى لاى الطلاب. 
1- إعداد اختبار المعارف المرتبطة بالتصنيع الغذائى لطلاب المدارس الثانوية الزراعية: تم اتباع الخطوات الثالية لبناء اختبار المعارف البيئية المرتبطة

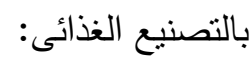
أ) هدف الاختبار: هدف الاختبار إلى قياس مدى اكتساب عينة من طلاب الددارس الثانوية الزراعية للمعارف البيئية المرتبطة بالتصنيع الغذائى والتى تضمنها البرنامج المقترح.

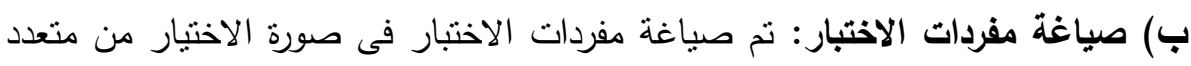

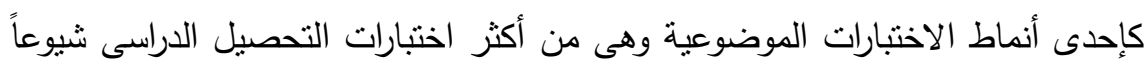

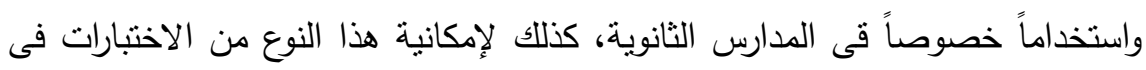

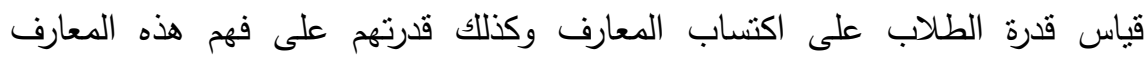

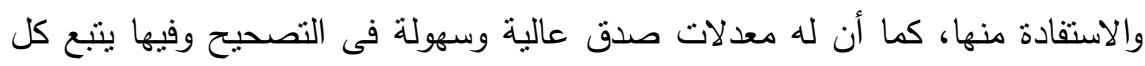

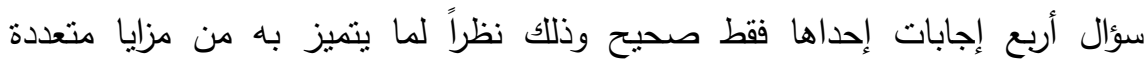

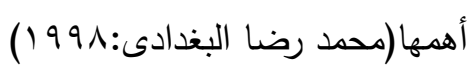

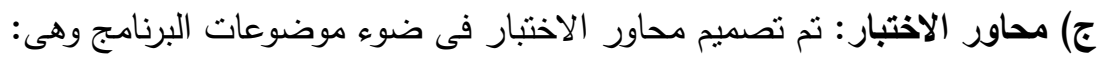

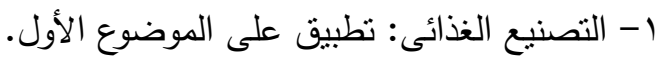

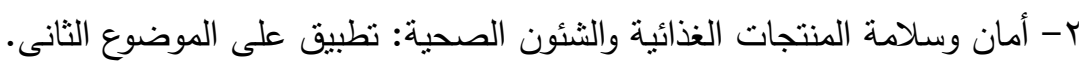

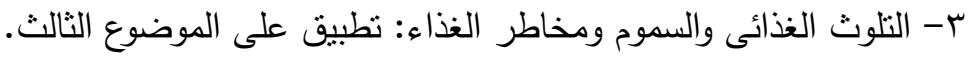

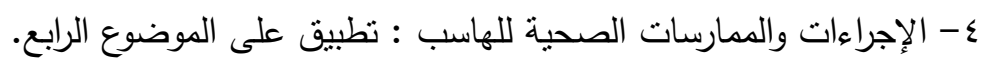

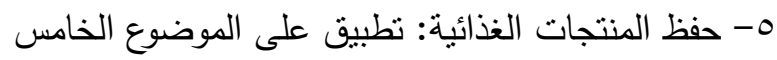


صابر محمود حسين وآخرون

جدول يوضح مدى ارتباط أسئلة الاختبار بدروس ومحاور البرنامج الوحدة التدريسية

\begin{tabular}{|c|c|c|c|c|}
\hline العدد & أرقام أسئلة الاختبار & المحور & موضوعات الاروس & ? \\
\hline 9 & $\leqslant V / \leqslant 0 / \Gamma V / \Gamma Y / \Lambda / T / \Sigma / T / 1$ & 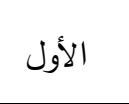 & أساسيات التصنيع الغذائى والعوامل & 1 \\
\hline 1. & 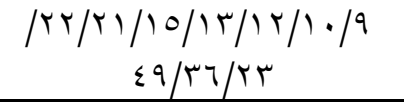 & 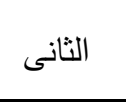 & العوامل البيئية المؤثرة على صلاحية المنائية & r \\
\hline $1 \pi$ & 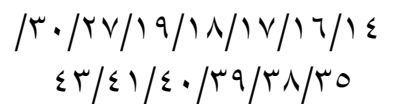 & 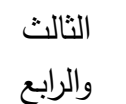 & تلوث المنتجات الغذائية وفسادها & $r$ \\
\hline$\Lambda$ & $\begin{array}{c}\mid \varepsilon \varepsilon / \varepsilon r / r \varepsilon / r r / r \cdot / N / V \\
\varepsilon T\end{array}$ & 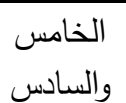 & الاشتراطات الييئية الصحية لسلامة & $\varepsilon$ \\
\hline 1. & 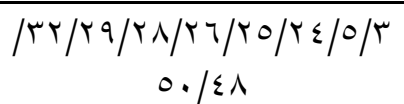 & 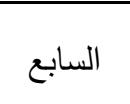 & طرق حفظ الأغذية & 0 \\
\hline 0. & & أسئُــلة & & \\
\hline
\end{tabular}

د) الصورة النهائية للاختبار: تم تعديل الاختبار فى ضوء بعض التغييرات والتعديلات بناءً

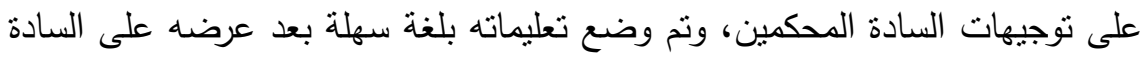

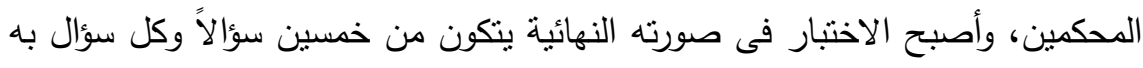

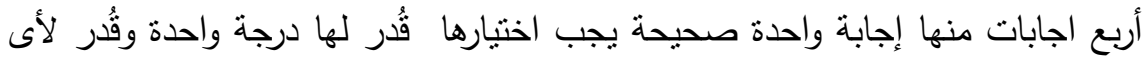

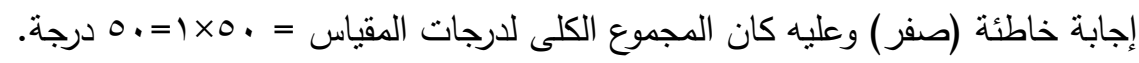
و) طريقة الإجابة ومفتاح الإجابة: يجب اختبار إجابة واحدة لكل سؤال كما حدد طريقة

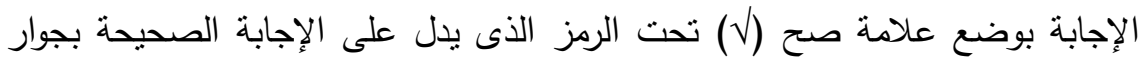

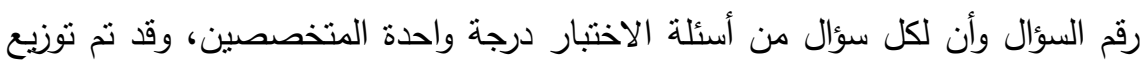

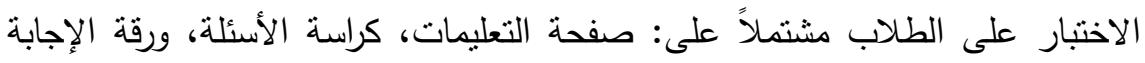
منفصلة وبها بيانات الطالب اللازمة.

صدق الاختباد : تم الاعتماد فى قياس صدق المقياس على الصدق الظاهرى، وذلك بعرضه على لجنة من المحكمين، وبذلك يتحقق صدق المقياس.

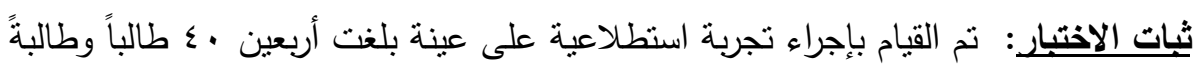

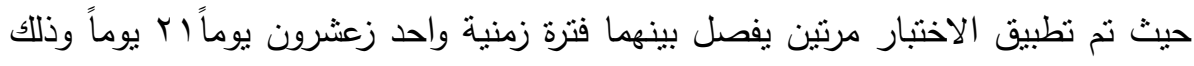




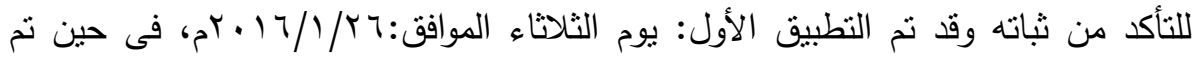

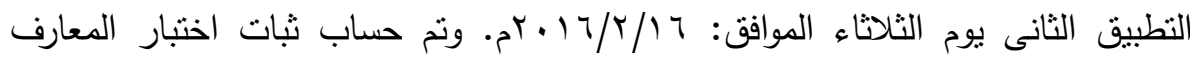

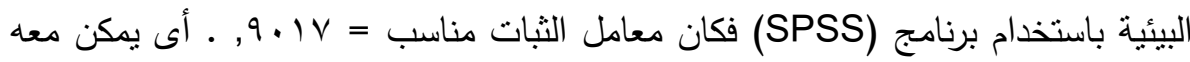
استخدام الاختبار والاعتماد عليه فى الدراسة، وبعد عرض الاختبار على السادة المحكمين

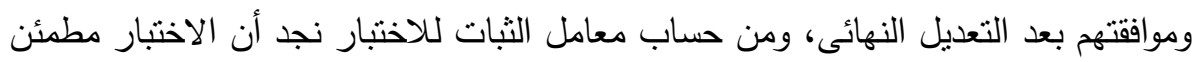

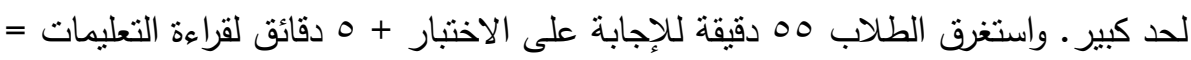

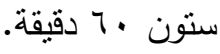

\section{r - تصميم بطاقة ملاحظة المهارات البيئية:}

أ) تحديد هدف بطاقة الملاحظة: هدفت البطاقة إلى قياس مستوى أداء مجموعة الدراسة للمهارات البيئية المرتبطة بالتصنيع الغذائى المتوفرة لديهم المجموعة التجريبية قبل

$$
\text { تطبيق البرنامج وبعده. }
$$

ب) محاور وابعاد البطاقة: الجدول التالى يبين محاور البطاقة والمهارات الرئيسة التى لتى تقيسعا المحاور والتى يندرج تحتها المهارات الفرعية وعدد تلك المهارات بالنسبة لكل

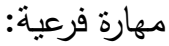

جدول: يبين مدى توافق مواقف بطاقة ملاحظة المهارات البيئية بالمجالات المهارية

\begin{tabular}{|c|c|c|c|c|}
\hline عدل المواقفة & المواقفل & المهارات & المهارات البيئية المرتبطة بالتصنيع & ? \\
\hline$\varepsilon$ & $\varepsilon: 1$ & 1 & استخدام الأدوات والآلات & 1 \\
\hline rT & M :0 & $\Lambda$ & التعامل مع الخضراوات & $r$ \\
\hline$\varepsilon$ & $\varepsilon \cdot: r V$ & 1 & الحكم على مدى جودة الأغذية & $r$ \\
\hline$\varepsilon$ & $\varepsilon \leqslant: \leqslant 1$ & 1 & ت تداول الغذاء & $\varepsilon$ \\
\hline 17 & $7 \cdot: \leqslant 0$ & $\varepsilon$ & مهارات حفظ المنتجات الغذائية & 0 \\
\hline$\Lambda$ & $7 \wedge: 71$ & $r$ & مهارات نفسحركية & 7 \\
\hline 17 & $\wedge \leq: 79$ & $\varepsilon$ & الممارسات الصحية البيئية الجيدة & $v$ \\
\hline 17 & $1 \cdots: 10$ & $\varepsilon$ & مهارات خاصنة بالبيانات المتعلقة & $\wedge$ \\
\hline & ro & إجمالى عدد أسئــلـة البطاقة & \\
\hline
\end{tabular}

406

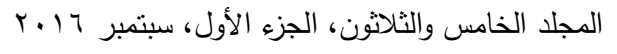




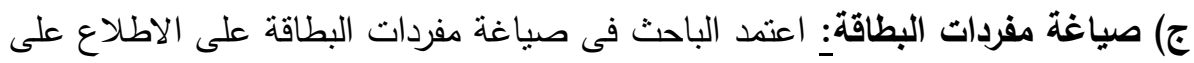
بحوث ودراسات سابقة تتاولت إعداد اختبارات تقيس المهارات وقد روعى فى مفردات اتبهات البطاقة: أن تكون سهلة وبسيطة من الناحية اللغوية وبعيدة عن لغة الماضى، ومناسبة لمسنوى الطلاب

جدول: المهارات البيئية الواجب توافرها لدى طلاب المدارس الثانوية الزراعية

\begin{tabular}{|c|c|c|}
\hline المهارات الفرعية & المهارات الرئيسة & م \\
\hline 1- استخدام الأدوات والآلات والأجهزة والعناية بها. & استخدام الأدوات والآلات & 1 \\
\hline r- استلام الخضراوات، الألبان، الفواكه & \multirow{8}{*}{ التعامل مع المنتجات } & \multirow{8}{*}{ Y } \\
\hline r- غسل الخضراوات والفواكه & & \\
\hline ع- تقشيرالخضراوات والفاكهة & & \\
\hline 0- مهارة تقطيع الخضراوات والفاكهة. & & \\
\hline 7- مهارة تعليب الخضراوات والفاكهة. & & \\
\hline V - مهارة تعبئة الخضراوات والفاكهة & & \\
\hline 1- مهارة تغليف الخضراوات والفاكهة & & \\
\hline 9- مهارة تجفيف الخضراوات والفاكهة & & \\
\hline • 1 - تداول الغذاء بطريقة سليمة آمنة والتعامل معه & 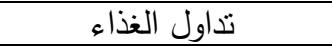 & $r$ \\
\hline |11- مهارة تقليد المعلم & \multirow{2}{*}{ مهارات نفسحركية } & \multirow{2}{*}{$\varepsilon$} \\
\hline r ا- مهارة تمبيز عبوات المنتجات الغذائية ومدى صلاحيتها & & \\
\hline المنخفضة مثل: (التبريد - التجميد). الغذائية باستخدام درجات الحرارة & \multirow{4}{*}{ مهارات حفظ المنتجات } & \multirow{4}{*}{0} \\
\hline مثل: (البسترة - التعقيم - الغليان الغذائية باستخدام درجات الحرارة المرتفعة & & \\
\hline 10- حفظ المنتجات الغذائية بالتحكم في درجة الرطوبة & & \\
\hline 7 ا - الحفظ بالمواد المضافة/الحافظة/الكيماويات/بالتدخين /بالتعليب & & \\
\hline V الكشف عن إصابة المنتجات الغذائية بالحشرات & \multirow{4}{*}{ الممارسات الصحية الليئية } & \multirow{4}{*}{7} \\
\hline 1/ إعادة التدوير مخلفات المنتجات الغذائية & & \\
\hline 9 19- المقارنة: بين طريقة حفظ وأخرى & & \\
\hline • . - مهارة عرض وتصنيف العينات المنتوعة & & \\
\hline ا اب- الحكم على مدى & الحكم علي مدى جودة & $\checkmark$ \\
\hline r r جمع البيانات والمعارف & \multirow{4}{*}{ مهارات خاصنة بالبيانات بالتصنيع الغذاتي } & \multirow{4}{*}{$\wedge$} \\
\hline rr- تتظيم المعارف البيئية المرتبطة بالتصنيع الغذائى وتحليلها & & \\
\hline ع ع - كتابة التقارير & & \\
\hline الدفاتر الخاصجة تسيل بيانات المنتجات الغذائية على العبوات وفى & & \\
\hline
\end{tabular}


د) الصورة النهائية للبطاقة: تم إعداد بطاقة ملاحظة المهارات البيئية النى تكونت من قائمة

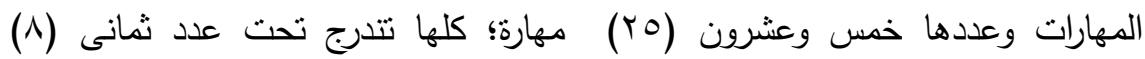
مهارات رئيسة، وقد تم ترجمة كل مهارة من مهارات القائمة الفرعية بأربعة مواقف سلوكية

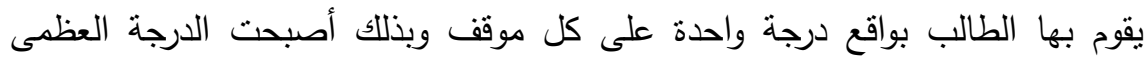
لبطاقة ملاحظة المهارات البيئية مائة ( . ( ) درجة.

هـ) صدق البطاقة: وقد تمثل تحقيق الصدق الظاهرى لبطاقة الملاحظة فى اتفاق السادة

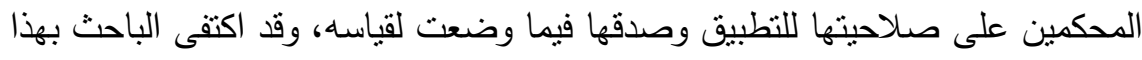

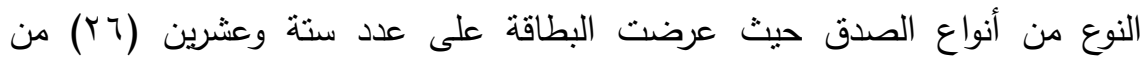
المحكمين من الخبراء والمتخصصين فى التربية البيئية والعلوم الزراعية البيئية والمناهج وطرق التدريس وأقروا بصلاحيتها وصدقها، وقد رأى بعض الدحكمون إعادة نرتيب

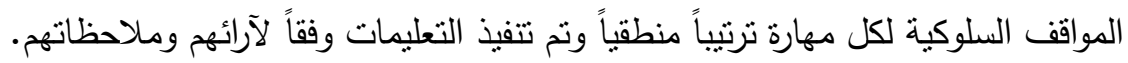

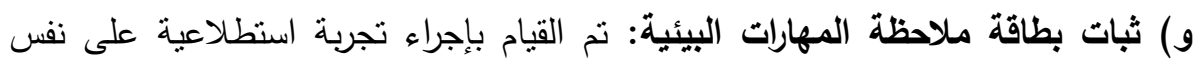
العينة التى تم تطبيق ثبات الاختبار عليها حيث تم تطبيق بطاقة الملاحظة مرتين

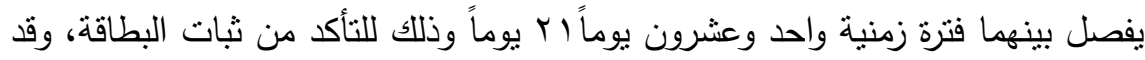
تم حساب ثبات بطاقة ملاحظة المهارات البيئية باستخدام برنامج (SPSS)، وكان

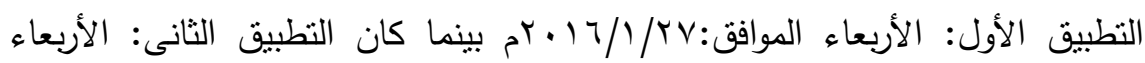

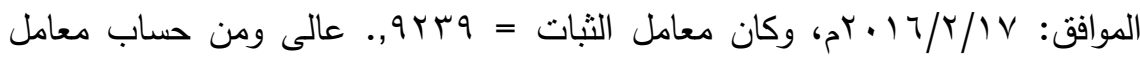
الثبات للبطاقة نجد أنه مطئن لحد كبير وقد استغرق النطبيق مائة ، ـ. 1 دقيقة. اختيار مجموعة الدراسة: أجريت الدراسة على عينة قوامها مائة ... طالب، خمسون •0 طالبة) جميعهم من المستويات المتوسطة فى التحصيل الدراسى (تم

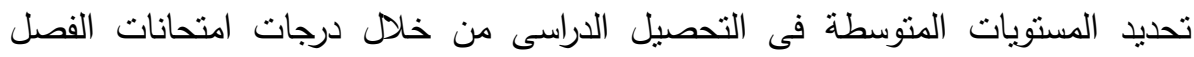
الدراسى الأول)، وتتراوح أعمارهم بين 10 - V اسنة (تم معرفة السن عن طريق دفاتر القيد)

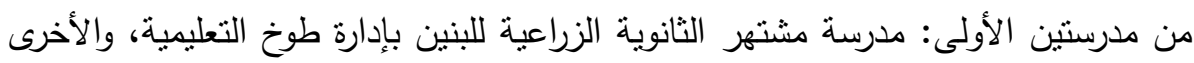


مدرسة التصنيع الغذائى للبنات بمسطرد بإدارة شرق شبرا الخيمة التعليمية والإدارتان بمحافظة القليوبية.

\section{إجراءات التطبيق}

أ) بعد النأكد من صدق وثبات اختبار المعارف البيئية، بطاقة ملاحظة المهارات البيئية ومعرفة الزمن اللازم لتطبيقهما بدأ النطبيق الفعلى على مجموعة الدراسة باستخدام

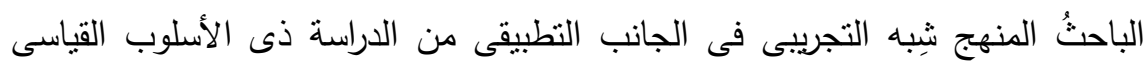
القبلى والبعدى لتطبيق وتدريس البرنامج، وتم تطبيق أداتى الدراسة (اختبار المعارف

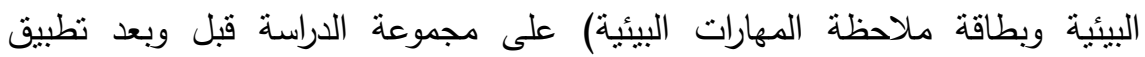
البرنامج؛ لإيجاد العلاقة بين متغيرين أحدهما مستقل وهو البرنامج المقترح، والآخر تابع وهو الوعى بالمعارف والمهارات البيئية.وقد تم التحقق من تكافؤ أفراد المجموعة قبل النطبيق.

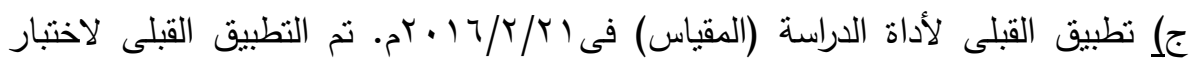

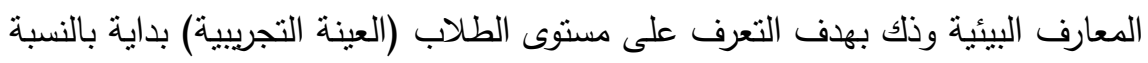
لكل من المعارف والمفاهيم البيئية، والمهارات البيئية قبل تدريس البرنامج.

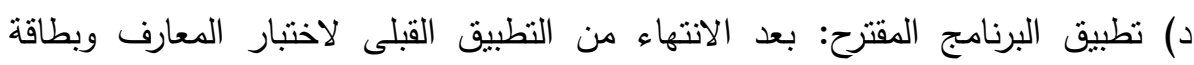

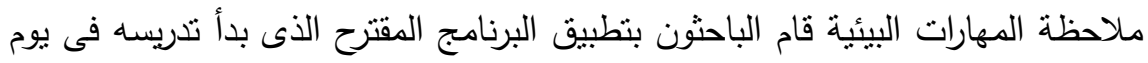

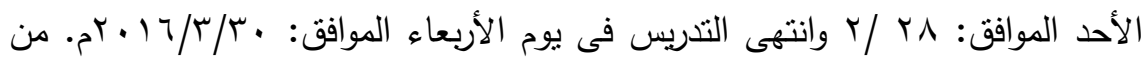

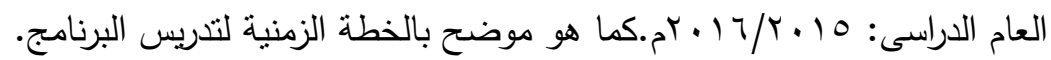
هـ) التطبيق البعدى لاختبار المفاهيم البيئية ومقياس المهارات البيئية ـ بعد الانتهاء مباثرةً

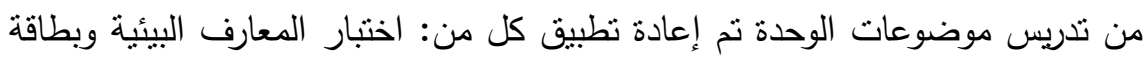
ملاحظة المهارات البيئية على نفس مجموعة الدراسة فى يومى الأحد والثلاثناء الموافقان:

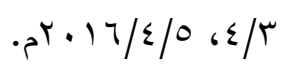

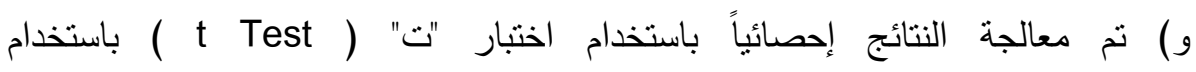

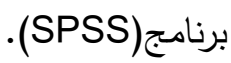


السؤال الرابع: ما فاعلية البرنامج المقترح فى تتمية الوعى بالمعارف والمهارات البيئية المرتبطة بالتصنيع الغذائى؟ مأى

للتحقق من فاعلية البرنامج المقترح بعد تطبيقه وتدريسه تم تثفيذ الخطوات الآتية: 1- إجراء القياس القبلى، ثم تدريس البرنامج، ثم إجراء القياس البعدى.

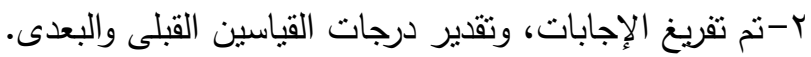

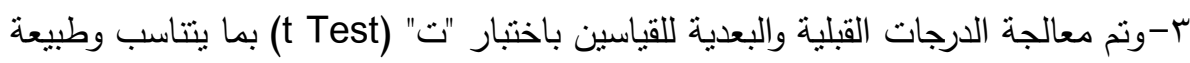
الدراسة وفروضها باستخدام برنامج (SPSS v20). للتحقق من صحة فروض الدارئه الداسة، وفاعلية البرنامج. وتم حساب نسبة الكسب المعدل لبلاك وتم حساب نسبة حجم الثأثير

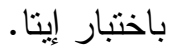

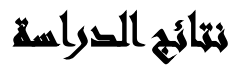

أوضحت المعالجة الإحصائية نتائج الدراسة من خلال برنامج (SPSS v20) على النحو

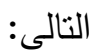

بالتحقق من صحة الفرض الأول: والذي ينص على أنه: يوجد فرق ذو دلالة إحصائية بين منوسطى درجات الطلاب قبل وبعد تطبيق البرنامج فى اختبار المعارف البيئية لصالح

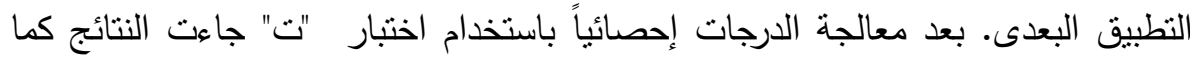

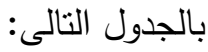

النتائج الإحصائية لارجات طلاب المجموعة التجريبية فى اختبار المعارف: (t Test Paired Sample Test) :(Test T) (ختبار

\begin{tabular}{|c|c|c|c|c|c|c|c|c|}
\hline الدلالة & قيمة " ت ت & الحرية & الانحراف & المئوية & المتوسط & الدرجات & أعراد & التطبيق \\
\hline$\cdot, .0$ & & & $1, v \leq \wedge$ & rr, & 17,00 & 1700 & $1 \ldots$ & التطبيق القبلى \\
\hline دالة & $M \cdot, V T \leq$ & 99 & $1,70 r$ & $\wedge r, 1 \wedge$ & $\leqslant 1,09$ & $\leqslant 109$ & $1 \ldots$ & التطبيق البعدى \\
\hline
\end{tabular}

المجلد الخامس والثلاثتن، الجزء الأول، سبتمبر 17 بـ 
وفيما يلى تفسير هذه النتائج ومناقشتها: من النتائج المستخلصة من الجدول السابق يتضح ما يلى: أ) ارتفاع مستوى تحصيل الطلاب للمعارف البيئية حيث بلغ متوسط درجات الطلاب فى البى الاختبار البعدى أكبر بكثير منه فى التطبيق القبلى، وهذا يدل على فاعلية البرنامج.

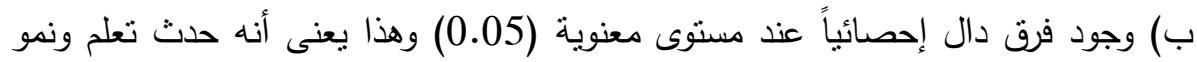
للمعارف البيئية وأن هذا التعلم لا يرجع للصدفة، وإنما يرجع إلى اكتساب الطلاب

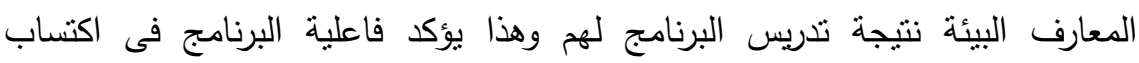
المعارف البيئية وبذلك يكون قد نم التحقق من صحة الفرض الأول، وكذلك الإجابة على لثاني السؤال الرابع من الدراسة.

الفروق فى محاورالاختبار ودلالتها: فيما يلى جدول نتائج الفروق فى محاورالاختبار

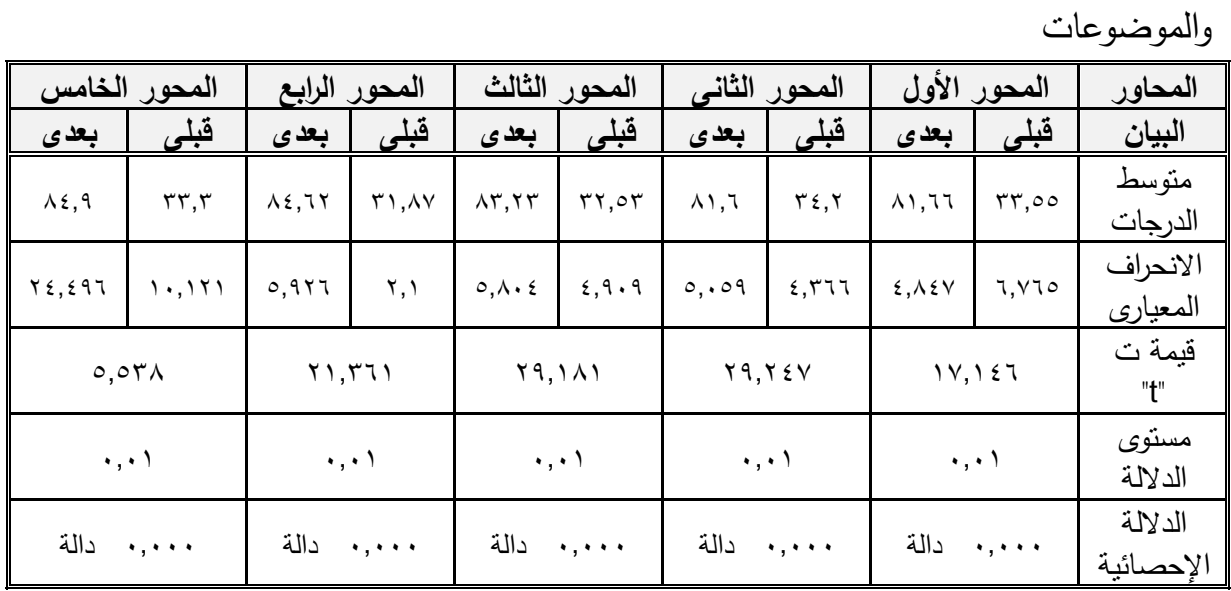

من جدول الفروف فى عدد الإجابات الصحيحة لأسئلة المحاور فى التطبيق القبلى

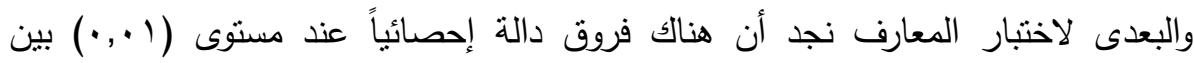
منوسطات الطلاب الذين أجابوا إجابات صحيحة لأسئلة كل محور فى التطبيق التهات القبلى والبعدى. 
1. للتحقق من صحة الفرض الثانى للاراسة :_وهو يوجد فرق ذا دلالة إحصائية بين متوسطى درجات الطلاب قبل وبعد تطييق البرنامج فى اكتساب الدهارات البيئية لصالح التطبيق البعدى. بعد معالجة الدرجات إحصائياً باستخدام اختبار جاءت النابن النتائج

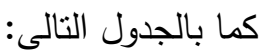

النتائج الإحصائية لدرجات طلاب المجموعة التجريية فى بطاقة ملاحظة المهارات البيئية

\begin{tabular}{|c|c|c|c|c|c|c|c|c|}
\hline الدلالدي & قاقيمة " تّ" & الررجية & الالانحراف & المئوية & المتوسط & الدجموع & عالعينذا أفراد & التطبيق \\
\hline \multirow{2}{*}{$\begin{array}{c}0.05 \\
\text { دالة }\end{array}$} & \multirow[b]{2}{*}{107,127} & \multirow[b]{2}{*}{99} & $r, Y T Y$ & 33,1 & 40,43 & $\varepsilon . \varepsilon T$ & $1 .$. & القبلي \\
\hline & & & $r, r r)$ & 85,6 & 85,6 & 107. & $1 \ldots$ & البعديقي \\
\hline
\end{tabular}

وفيما يلى تقسير هذه النتائج ومناقتنتها من النتائج المستخلصة من الجدول السابق

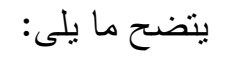
أ) ارتفاع مستوى المهارات البيئية التى اكتبها الطلاب فى التطبيق البعدى أعلى منه فى

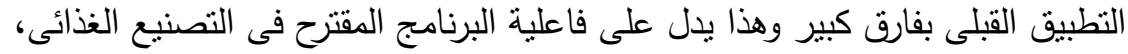

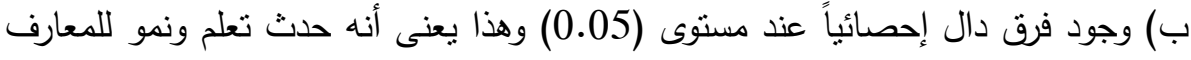
البيئية وأن هذا النعلم والنمو لا يرجع لعامل الصدفة، وإنما برجع إلى اكتساب الطلاب الناب

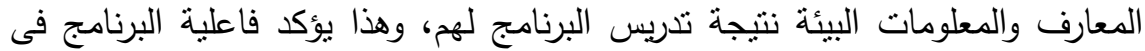

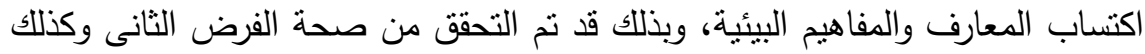

$$
\text { الإجابة على السؤال الخامس من أسئلة الدراسة. }
$$

ثالثاً: للتحقى من صحة الفرض الثالث: وهو يوجد معامل ارتباط ذو دلالة إحصائية بين متوسطى درجات الطلاب فى كل من اختبار المعارف البيئية وفى بطاقة ملاحظة المهارات البيئية فى التطبيق البعدى. بعد معالجة الدرجات باستخدام اختبار ارتباط بيرسون

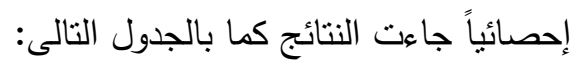


صابر محمود حسين وآخرون

جدول: الارتباط بين درجات اختبار المعارف ودرجات بطاقة ملاحظة المهارات البعدية

\begin{tabular}{|c|c|c|}
\hline معامل الارتباط & المتوسط & التطبيق \\
\hline \multirow[b]{2}{*}{$\cdot, 994$} & 41,59 & قياس الاختبار البعدى \\
\hline & 10,7 & قياس بطاقة الملاحظة البعدى \\
\hline
\end{tabular}

ويتضح من الجدول السابق: قوة الارتباط بين اختبار المعارف البيئية البعدى وبطاقة ملاحظة المهارات البيئية بمعامل ارتباط بيرسون (Pearson Correlation test) وجد أن النئين نسبته عالية (ارتباط عالى موجب). تفسير ومناقشة الفرض الثالث للاراسة:

أ) توجد علاقة ارتباط حقيقية عالية جداً موجبة بمستوى دلالة (0,05) بين درجات اختبار المعارف البيئية ودرجات بطاقة ملاحظة المهارات البيئية فى التطبيق البعدى ، نتيجة تدريس البرنامج وممارسة الأنشطة أدى ذلك إلى نمو فى المهارات البيئية المرتبطة

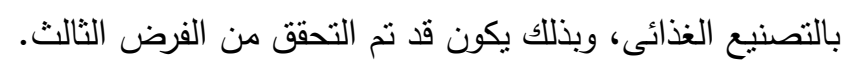

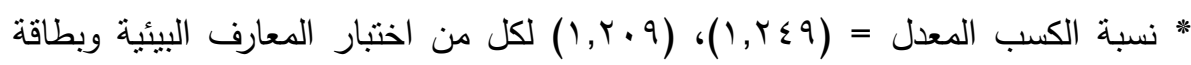

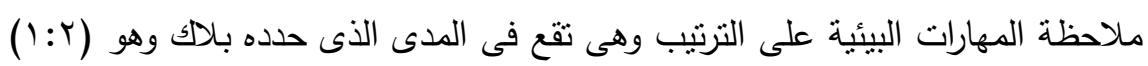
مما يثير إلى فاعلية البرنامج فى إكساب الطلاب المعارف والمهارات البيئية.

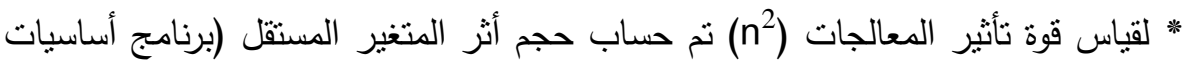
التصنيع الغذائى) على المتغير التابع تتمية المعارف البيئية وجد أنه = حجم التأثنر كبير بينما حجم أثز المتغير المستقل (برنامج أساسيات التصنيع الغذائى) على المتغير التابع تتمية المهارات البيئية (n²) وجد أنه = 0.99 أى أن أن حجم التأثنر كبير أيضاً.

التعقيب على النتائج: دلت نتائج المعالجة الإحصائية لاختبار المعارف وبطاقة ملاحظة المهارات البيئية أنه حدثت تتمية لمستوى المعارف والمهارات البيئية لاى طلاب المدارس الإس البه الثانوية الزراعية وبذلك تحقتث فاعلية البرنامج المقترح، وهذا يرجع إلى الإعداد الجيد لها؛

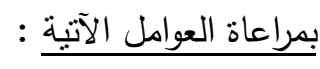


1 - تهيئة المناخ الملائم وإتاحة الفرص المتساوية للاشتراك فى الأنشطة والمناقثة الفعالة. r- استثارة دافعية الطلاب من خلال ربط الموضوعات بخبراتهم الحياتية والعملية فأدى ذلك الك

$$
\text { إلى زيادة الفعالية والإيجابية. }
$$

r- إثراء البرنامج المقترح بالأنشطة التعليمية منل: زيارة ميدانية لمصنع المنتجات الغذائية بقرية قها مركز طوخ بمحافظة القليوبية. ع- استمرار عملية التقويم وتتوع أساليبه الذى بدأ مع بداية تدريس كل موضوع من من ماته موضوعات الوحدة الدراسية مما كان له الأثر البالغ فى تصحيح أداء الطلاب علئ علينة الدراسة أولاً بأول من خلال التغذية الراجعة.

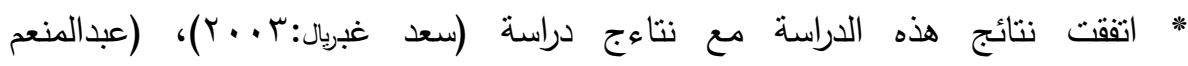

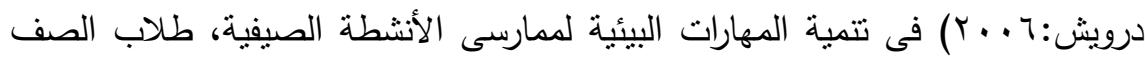

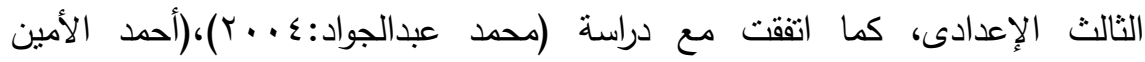

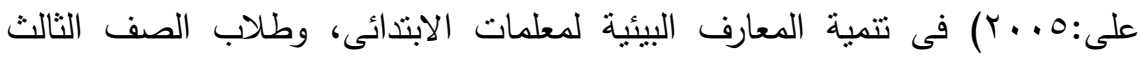
الإعدادى فى ليبيا.

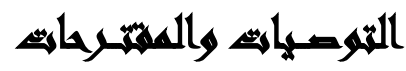

التوصيـات: فى ضوء ما توصلت إليه الدراسة من نتائج نوصى الدراسة بما يلى: 1- تضمين البعد البيئى والمصطلحات والمعارف البيئية الواردة بالدراسة الحالية بمناهج التعليم وخاصة التعليم الثانوى الفنى الزراعى" مجال التصنيع الغذائى" للاستفادة من بن لئه

$$
\text { البرنامج المقترح }
$$

r- ضرورة تعاون وزارات التربية والتعليم ووزارة الزراعة، ومنشأت التصنيع الغذائى، والجهات المسئولة عن الثروة الحيوانية، والنباتية، والصناعات الغذائية، والصناعات المغذية، والمكملة لها لخدمة طلاب المدارس الثانوية الزراعية بما يفيدهم وينمى معارفهم ومهاراتهم البيئية خارج المقررات بالكتب وخارج بيئة المدرسة (كزيارات المصانع 
محاضرات المختصين من تلك الجهات وتوزيع مذكرات تشرح طرق العمل بالأسواق فى مجال التصنيع الغذائى).

r- انباع طرق التدريس الحديثة، والمتتوعة بالاستعانة بالوسائل التكنولوجية، والزيارات الميدانية، بعيداً عن الطرق التقليدية للتدريس فى مدارس التعليم الزراعى. المقترحات: فى ضوء نتائج الدراسة الحالية تقدم الدراسة المقترحات التالية:

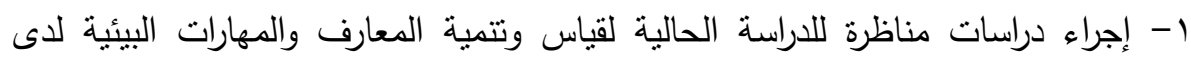

$$
\text { معلمى المدارس الثانوية الزراعية. }
$$

r- إجراء دراسات مناظرة للاراسة الحالية؛ لتتمية المعارف، والمهارات البيئية لدى طلاب الدابه

$$
\text { التعليم الثانوى بجميع أنواعه. }
$$

ץ- إعداد دراسات مقارنة؛ لقياس المعارف، والمهارات البيئية بين طلاب التعليم الثانوى العام

$$
\text { والفنى وكذلك بين طلاب التعليم الفنى بجميع أنواعه (زراعى - تجارى - صناعى). }
$$

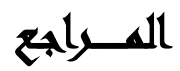

ابتسام أحمد عبدالعال(9 . . r): أثز تضمين بعض المفاهيم البيئية فى منهج اللغة الأسبانية

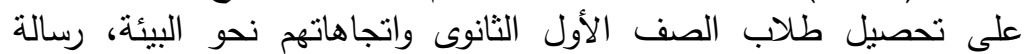
ماجستير ، جامعة عين شمس، معهد الدراسات والبحوث البهان البيأئية.

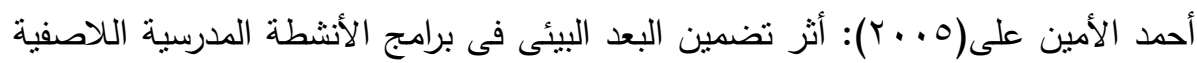

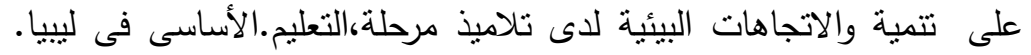

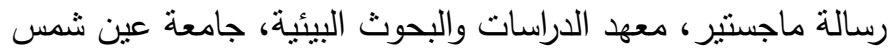

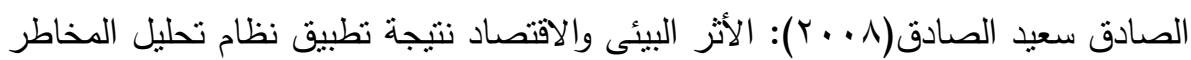

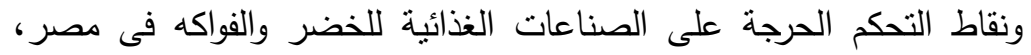
رسالة دكتوراه، معهد الدراسات والبحوث البيئية، جامعة عين شمس.

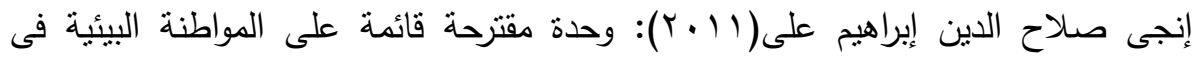

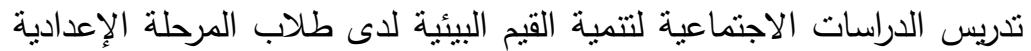

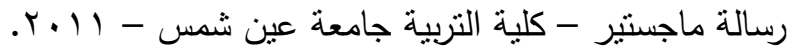

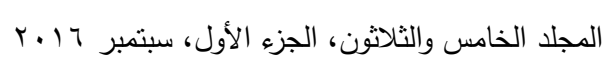


إيمان صالح عبد الماجد العباسى(9 . . ب): فاعلية استخدام المدخل البيئى فى تتمية المفاهيم

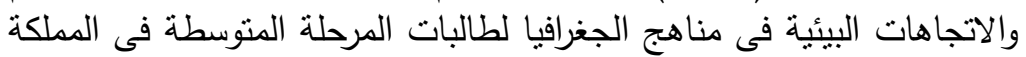

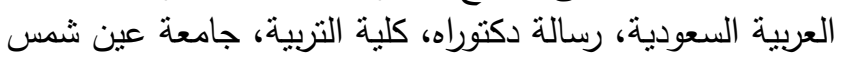

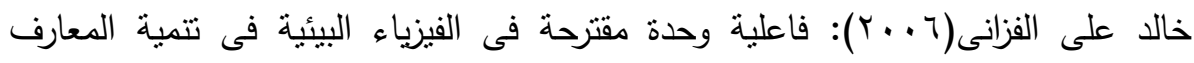

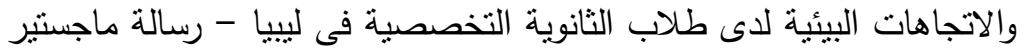
جامعة عين شمس، معهز الدراسات والبحوث البيئية.

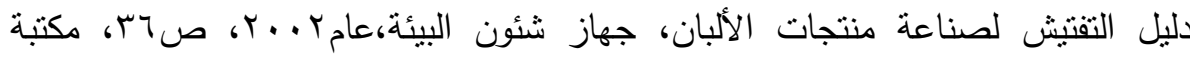
الجهاز

فائزة رجب محمد على(9 . ب): تتمية المهارات البيئية لاى تلاميذ المدرسة الإعدادية

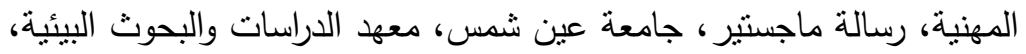

$$
\text { قسم العلوم التزبوية والإعلام البيئى. مائى }
$$

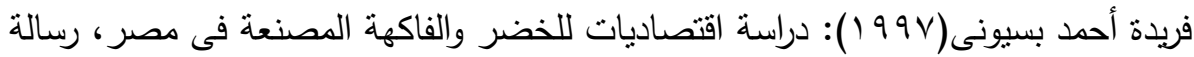
ماجستير ، كلية الزراعة، جامعة القاهرة، داستة

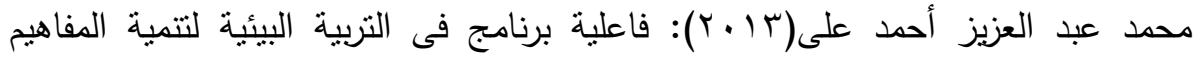

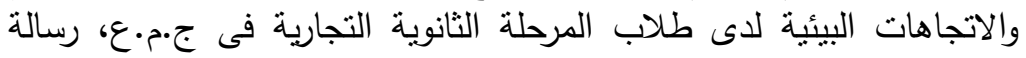
دكتوراة، جامعة المنوفية، معهد الدراسات والبحوث البيئية، فرع السادات.

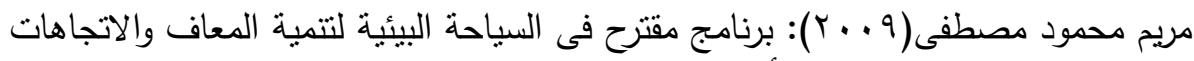

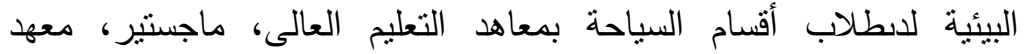
الدراسات والبحوث البيئية، جامعة عين شمس.

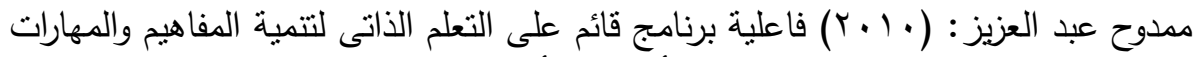

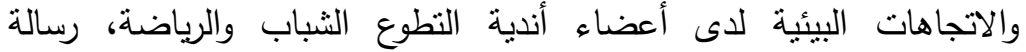
ماجستير ، معهد الدراسات والبحوث البيئية، جامعة عين شمس.

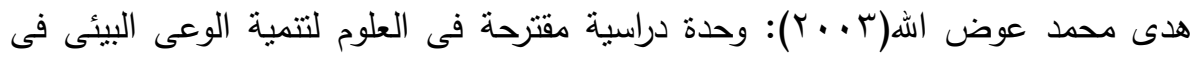

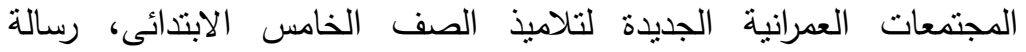
ماجستير ، جامعة عين شمس، كلية البنات

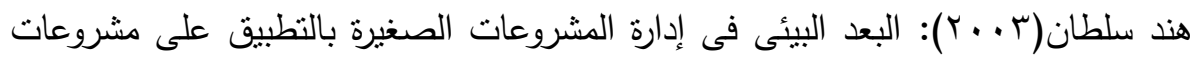

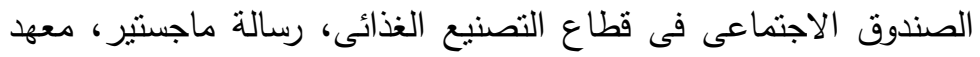

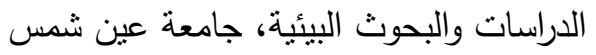


صابر محمود حسين وآخرون

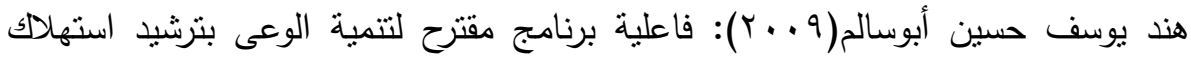

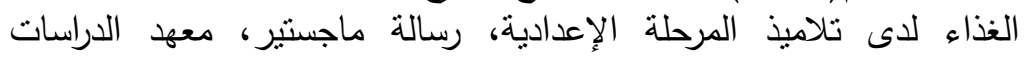

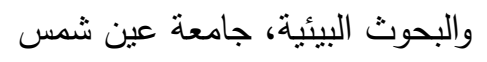

هيام عطا اله هاشم(1) (ب): دراسة المشكلات البيئية والاقتصادية لقطاع الصناعات

الغذائية لمدينة ج أكتوبر ، رسالة ماجستير ،معهد الدراسات والبحوث البيئية،

جامعة عين شمس.

Cesario, Karrie Marie (2004): Promotion of plant based foods to reduce risk of chronic disease, $\mathrm{Ph} . \mathrm{D}$. degree, University of

California, Davis, Dissertation Abstract International, B65/08.

Christine Mosley.(2002): "The effect of teachingout doorenvironmental education on preservice teacher's itudes

Codex Alimentarius (2001): Vol.1B General requirements (Food hygiene)

Codex Alimentarius (2001): Vol.8 (Fats,oil and related products) $2^{\text {nd }}$ Ed

Kallio, Abby Kyrel (2003): Does nutrition education impact calcium intake and Bone mineral density in children, MS degree, Texas woman's university Denton, Texas, Dissertation Abstract International

Princess Abdul Latif Abdul Azim (2002): an educational program proposal for a food prep schoolers who suffer from iron deficiency anemia Unpublished MA Thesis - Faculty of Home Economics - Menoufia University

Propiotic Dairy Products (2005): Tamime, A. Y. by Blackwell Publishing Ltd

Stapp, william band darothy, ACox, Environmental Education Manual,Vol. I Concernining spaceship Earth Opcit, p11

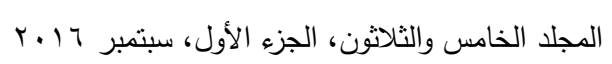


Verses Mohammed Ibrahim (2002): The effect of diet program and educational information on food trends for the students of secondary schools Menofia, Unpublished MA Thesis, Faculty of Home Economics - Menoufia University

WWW.google.gov.eg

\title{
A PROPOSED PROGRAM FOR DEVELOPING \\ ENVIRONMENTAL KNOWLEDGE AND SKILLS \\ ASSOCIATED WITH FOOD PROCESSING AMONG \\ AGRICULTURAL SECONDARY SCHOOL STUDENTS
}

Hussein, S. M. ${ }^{(1)}$; Mostafa, O. E. ${ }^{(2)}$ and Hassan, A. M. ${ }^{(3)}$

1) Faculty of Education, Ain Shams University 2) Faculty of Specific Education, Ain Shams University 3) The Ministry of Education.

\begin{abstract}
This study drives at developing awareness of knowledge and environmental skills associated with food manufacturing among students of agricultural secondary stage. The researcher has fulfilled his study by reviewing literatures and established a pilot study for tackling these topics. The study uses several tools including the Environmental Knowledge Test, Observation Card of Environmental Skills associated, and A Proposed Program For Developing Environmental Knowledge And Skills Associated With Food Processing. with nutritional industrialization, to be applied on a sample of (100) male/female students of secondary agricultural schools in Qaluibyia governorate Using experimental Curriculum Tools are applied pre/post the proposed program. The study. comes to

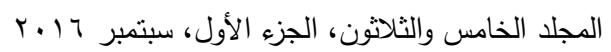


these results: There is a significant statistical difference at (0.05) between average scores of Students study group regarding the pre/post application of the Environmental Knowledge Test and Observation Card of Environmental Skills in favor of the post application.

There is a very highly positive correlation at $(0.01)$ between average scores of students on Environmental Knowledge Test, Observation Card of Environmental Skills and The treatment impact is calculated and so the impact of the independent variable (0.99) to tow study tools (the Environmental Knowledge Test, Observation Card of Environmental Skills)

It was further calculate average percentage gain was (1.249) for the Environmental Knowledge Test, while the ratio (1.2099) Observation Card of Environmental Skills. The study recommends:

1- Include the environmental dimension and environmental terms and knowledge contained the present study methods of education, especially technical secondary education Agricultural "field of food processing," to take advantage of the proposed program

2. The need for Ministries of Education and the Ministry of Agriculture Cooperation, facilities and food processing, and those responsible for livestock, and vegetable, and food industries, and industries nutrients, and complementary to serve the agricultural high school students, including benefits them and develop their knowledge of environmental and skills outside courses to books and outside the school environment (such as traffic

factories lectures specialists from those actors and distribution of memoranda explaining the ways of working markets in the field of food processing)

3. follow modern teaching methods, and varied with the help of technologic4l means, field visits, away from traditional teaching in the agricultural education schools roads.

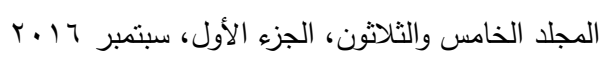

